\title{
YWHA (14-3-3) protein isoforms and their interactions with CDC25B phosphatase in mouse oogenesis and oocyte maturation
}

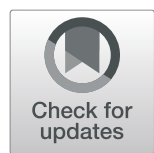

\author{
Alaa A. Eisa ${ }^{1 \dagger}$, Santanu De ${ }^{2 \dagger}$, Ariana Detwiler ${ }^{3}$, Eva Gilker ${ }^{4}$, Alexander C. Ignatious ${ }^{5}$, Srinivasan Vijayaraghavan ${ }^{5}$ and \\ Douglas Kline ${ }^{5^{*}}$ (D)
}

\begin{abstract}
Background: Immature mammalian oocytes are held arrested at prophase I of meiosis by an inhibitory phosphorylation of cyclin-dependent kinase 1 (CDK1). Release from this meiotic arrest and germinal vesicle breakdown is dependent on dephosphorylation of CDK1 by the protein, cell cycle division 25B (CDC25B). Evidence suggests that phosphorylated CDC25B is bound to YWHA (14-3-3) proteins in the cytoplasm of immature oocytes and is thus maintained in an inactive form. The importance of YWHA in meiosis demands additional studies.

Results: Messenger RNA for multiple isoforms of the YWHA protein family was detected in mouse oocytes and eggs. All seven mammalian YWHA isoforms previously reported to be expressed in mouse oocytes, were found to interact with CDC25B as evidenced by in situ proximity ligation assays. Interaction of YWHAH with CDC25B was indicated by Förster Resonance Energy Transfer (FRET) microscopy. Intracytoplasmic microinjection of oocytes with R18, a known, synthetic, non-isoform-specific, YWHA-blocking peptide promoted germinal vesicle breakdown. This suggests that inhibiting the interactions between YWHA proteins and their binding partners releases the oocyte from meiotic arrest. Microinjection of isoform-specific, translation-blocking morpholino oligonucleotides to knockdown or downregulate YWHA protein synthesis in oocytes suggested a role for a specific YWHA isoform in maintaining the meiotic arrest. More definitively however, and in contrast to the knockdown experiments, oocytespecific and global deletion of two isoforms of YWHA, YWHAH (14-3-3 eta) or YWHAE (14-3-3 epsilon) indicated that the complete absence of either or both isoforms does not alter oocyte development and release from the meiotic prophase I arrest.
\end{abstract}

Conclusions: Multiple isoforms of the YWHA protein are expressed in mouse oocytes and eggs and interact with the cell cycle protein CDC25B, but YWHAH and YWHAE isoforms are not essential for normal mouse oocyte maturation, fertilization and early embryonic development.

Keywords: Meiosis, Oogenesis, Oocyte maturation, YWHA, 14-3-3, YWHAH, YWHAE, CDC25B, Mouse

\section{Introduction}

Oocytes are held in the first meiotic prophase within the mammalian ovary. Prophase arrest is dependent on the production of cAMP within the oocyte. Constitutively active heterotrimeric $G$ protein receptors linked to stimulatory $\mathrm{G}$ proteins activate adenylyl cyclase to maintain a high concentration of cAMP within the oocyte

\footnotetext{
* Correspondence: dkline@kent.edu

${ }^{\dagger}$ Alaa A. Eisa and Santanu De contributed equally to this work.

${ }^{5}$ Department of Biological Sciences, Kent State University, Kent, OH 44242, USA

Full list of author information is available at the end of the article
}

[1-3] reviewed by Jaffe and Egbert [4]. Meiotic arrest is maintained by cAMP-dependent activation of protein kinase A (PKA), in part, by phosphorylating and activating the oocyte-specific kinase WEE2 (also known as WEE1B) [5-8]. WEE2, in turn, is thought to phosphorylate and inactivate cyclin-dependent kinase 1 (CDK1), which together with regulatory cyclin B1 (CCNB1), forms maturation promoting factor (MPF) reviewed in $[9,10]$. MPF is well characterized, based on studies of oocytes of many species as well as somatic cells, since it is the cell cycle regulatory factor for both meiotic and

(c) The Author(s). 2019 Open Access This article is distributed under the terms of the Creative Commons Attribution 4.0 International License (http://creativecommons.org/licenses/by/4.0/), which permits unrestricted use, distribution, and 
mitotic cells reviewed in [11-13]. Inhibitory phosphorylation of CDK1 maintains MPF in an inactive state within the oocyte. PKA is also thought to phosphorylate cell division cycle 25B (CDC25B) phosphatases [14-16], keeping $\mathrm{CDC} 25 \mathrm{~B}$ proteins in an inactive state that preserves the phosphorylated and inactive status of CDK1 a target of $\mathrm{CDC} 25 \mathrm{~B}$. In the arrested mouse oocyte, genetic studies have shown that $\mathrm{CDC} 25 \mathrm{~B}$, and not CDC25C, is the primary phosphatase regulating the dephosphorylation of CDK1, $[17,18]$ although CDC25A also appears to play a role in oocyte maturation [19].

The high level of cAMP in the follicle-enclosed oocyte, generated by the oocyte itself, is sustained by cGMP produced in granulosa cells, which passes through gap junctions and inhibits the hydrolysis of cAMP by the cAMP phosphodiesterase, PDE3A [20]. Oocytes in pre-ovulatory follicles resume meiosis in response to luteinizing hormone (LH) acting on granulosa cells. LH initiates multiple signaling pathways including the interruption of the flow of inhibitory cGMP by inactivation of the NPR2 guanylyl cyclase and stimulation of cGMP hydrolysis by activation of a phosphodiesterase [4]. Activation of the cAMP phosphodiesterase within the oocyte reduces cAMP level and PKA activity. MPF is activated following reduced phosphorylation by WEE2 and the dephosphorylation of CDK1 by the protein phosphatase, CDC25B, reviewed in [10]. Activation of MPF initiates the resumption of meiosis and the process of oocyte maturation beginning with nuclear envelope breakdown (germinal vesicle breakdown or GVBD) followed by formation of the first polar body and, in most mammals, arrest at metaphase of the second meiotic division, reviewed in [21, 22]. Oocyte maturation forms the mature egg and fertilization releases the egg from metaphase II arrest, allowing formation and development of the zygote.

The phosphorylation and activity of $\mathrm{CDC} 25$ proteins appears to be preserved, in part, by binding to YWHA regulatory proteins (Tyrosine 3-Monooxygenase/Tryptophan 5-Monooxygenase Activation protein or 14-3-3). YWHA proteins are thought to both maintain the phosphorylated status of CDC25 and sequester CDC25 in the oocyte cytoplasm. Early studies demonstrated that, in Xenopus oocytes, CDC25 phosphatase is phosphorylated by PKA, and is bound to and sequestered by YWHA in the cytoplasm [23], thus maintaining the cell cycle arrest. Numerous studies implicate YWHA as a critical regulator of the cell cycle in meiotic and mitotic cells as well as other cellular processes [24-35]. The YWHA proteins also have multiple binding partners in mammalian testes and sperm [36, 37]. A YWHA protein also appears to bind to and likely regulate peptidyl arginine deiminase type VI (PADI6) in mice and humans [38, 39].

The YWHA proteins are a highly conserved, homologous family of proteins shown to bind to various cellular proteins and complement or supplement intracellular events involving phosphorylation-dependent switching or protein-protein interaction [33, 40]. Most of the binding partners of YWHA are phosphorylated; however, some interactions of YWHA do exist independent of phosphorylation [41]. The YWHA proteins exist mainly as homo- or hetero-dimers with a monomeric molecular mass of approximately $30 \mathrm{kDa}$ [33]. There are seven mammalian isoforms of YWHA encoded by separate

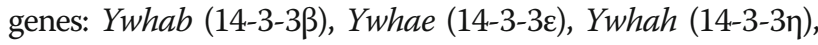

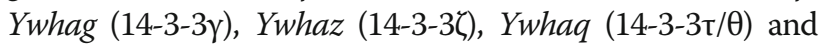
Sfn (14-3-3б).

Using isoform-specific antibodies, we found that all seven mammalian isoforms of YWHA are expressed in mouse ovaries, immature oocytes and mature eggs [42]. In contrast, one report indicated that only YWHAB and YWHAE are present in mouse oocytes [43]. This was surprising since our panel of antibodies had identified more isoforms and, for example, transcripts of at least six isoforms of $Y w h a$ are present in mouse eggs [44] and all seven $Y w h a$ isoform messages are found in human eggs $[45,46]$. In this report, we include additional evidence for the presence of Ywha mRNA for seven isoforms of YWHA in two different mouse strains.

It is known that different isoforms of YWHA can interact with the same ligand and so are somewhat interchangeable; however, although isoforms of YWHA often bind the same protein, there are some indications that homodimers of different types or even heterodimers of YWHA may have different roles in the regulation or sequestering of proteins [41]. Therefore, it is important to determine which YWHA isoform(s) interact(s) with $\mathrm{CDC} 25 \mathrm{~B}$ in the oocyte to maintain the meiosis I arrest. We examined YWHA-CDC25B interactions using in situ Proximity Ligation Assay (PLA) and Förster Resonance Energy Transfer (FRET) approaches.

We performed experiments to inhibit YWHA interactions with target proteins by injection of the YWHAinhibitory peptide, R18. In exploratory work shown here, we aimed to reduce the expression of specific YWHA proteins by intracellular microinjection of a translationblocking morpholino oligonucleotide against each of the YWHA isoform mRNAs. To definitively clarify a role of YWHAH and YWHAE, we generated oocyte-specific and global knockout mice in which genes for Ywhah, Ywhae, or both, were disrupted. Other previous reports of global Ywha knockouts of different isoforms have given limited information about oogenesis. The Ywhag knockout shows no abnormal phenotype, although it is not clear that reproductive potential was examined in detail [47]. With complete germline deletion of Ywhae in a global knockout, mice die at birth, due to cardiac malformations or other causes [48, 49] with prenatal embryos showing hippocampal and cortical defects in 
the brain [49]. Ywhaz knockout mice also show neurological defects $[50,51]$.

The experiments outlined in this work provide evidence that multiple YWHA isoforms interact with $\mathrm{CDC} 25 \mathrm{~B}$ in mouse oocytes and mature eggs and report for the first time on mice with two of the Ywha genes inactivated. The results indicate that oocyte-specific or global elimination of YWHAH protein does not result in abnormal fertility, oocyte maturation or development. Oocyte-specific or global elimination of YWHAE does not alter oocyte maturation, in vitro fertilization and early development, though global inactivation of Ywhae does appear to impair in vivo fertility.

\section{Results}

Detection of mRNAs for Ywha isoforms in mouse oocytes and eggs

It has been reported earlier that all seven YWHA proteins are expressed in mouse oocytes and eggs, based on the use of isoform-specific antibodies [42]. To confirm this observation, the presence of mRNA for all the isoforms was examined in both oocytes and eggs. Isoformspecific primers were used to amplify the messages for the seven isoforms by RT-PCR (Fig. 1). Messages for six of the seven mammalian isoforms were found in oocytes of both outbred ICR(CD-1) and inbred C57BL/6 J strains. Message for the seventh isoform, Sfn (14-3-3б) was just detected in oocytes of $\operatorname{ICR}(\mathrm{CD}-1)$ mice, but it was not detected in the $\mathrm{C} 57 \mathrm{BL} / 6 \mathrm{~J}$ strain. In a parallel experiment, we sequenced the RT-PCR products using specific forward and reverse primers. We obtained sequence data for $H 2 a f z$ mRNA and all isoforms of $Y w h a$ except $S f n$, as the product yield for $S f n$ cDNA was too low for accurate sequencing. As expected, $50-60 \%$ of the expected short PCR product was reliably sequenced and for each sequence the valid base calls exactly matched the NCBI mouse mRNA RefSeq sequences.

We also examined existence of the $Y w h a$ transcripts in mouse oocytes of ICR(CD-1) wild-type mice and several knockout models by mRNA sequencing of single oocytes (Table 1). Reads from RNA-seq were annotated to Ensembl. FPKM (fragments per kilobase of exon model per million reads mapped), the normalized estimation of gene expression based on the RNA-seq data, was estimated using Cufflinks. Messages for all seven isoforms of $Y w h a$ were detected (though Sfn is not as abundant). While the data is based only on one cell of each type, the FPKM values are similar among five cells examined, expect for those cells in which Ywhah and/or Ywhae genes were inactivated.

FPKM values for $Y w h a$ isoform transcripts in single oocytes were obtained from an ICR(CD-1) wild-type female, and from females with the Ywhae oocyte-specific

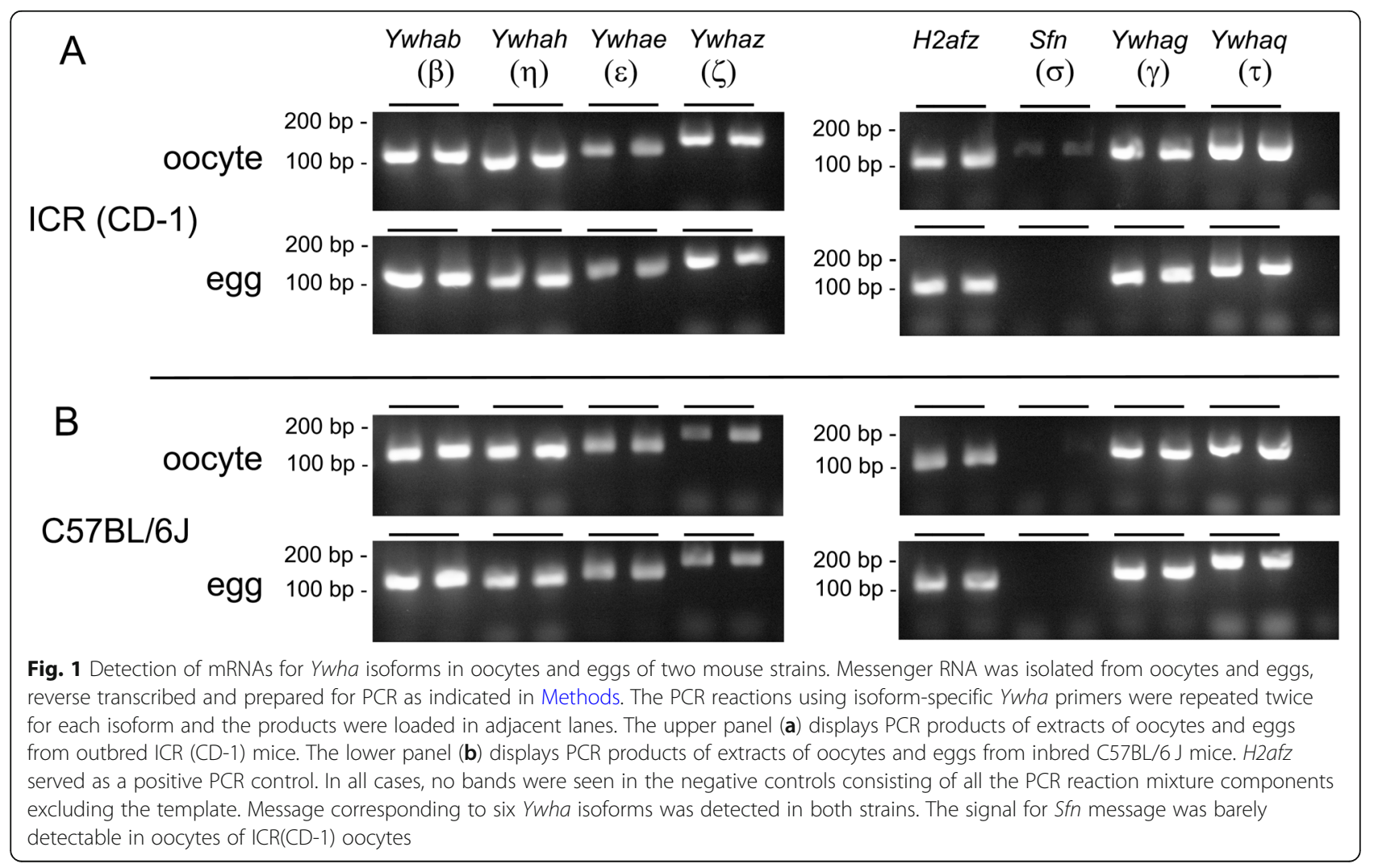


Table 1 Detection of Ywha isoform mRNAs in single oocytes

\begin{tabular}{llllllll}
\hline & YWHAH & YWHAE & YWHAQ & YWHAZ & YWHAB & YWHAG & SFN \\
\hline Wild type & 63.7 & 365.1 & 75.1 & 132.5 & 58.9 & 23.4 & 2.7 \\
Ywhae CKO & 61.7 & $(13.1)$ & 52.4 & 96.8 & 44.5 & 23.4 & 4.3 \\
Ywhah CKO & $(0.6)$ & 323.7 & 87.3 & 126.3 & 47.8 & 19.5 \\
Ywhae and Ywhah CKO & $(0.5)$ & $(18.3)$ & 119.0 & 97.5 & 48.1 & 13.3 & 7.6 \\
Ppplcc KO & 44.6 & 309.2 & 47.8 & 89.8 & 35.5 & 5.6 & 1.8 \\
Mean & $56.7 \pm 10.5$ & $332.7 \pm 29.0$ & $76.4 \pm 28.8$ & $108.6 \pm 19.4$ & $47.0 \pm 8.4$ & $14.6 \pm 7$ & $4.8 \pm 2.7$ \\
& $n=3$ & $n=3$ & $n=5$ & $n=5$ & $n=5$ & $n=5$ & $n=5$ \\
\hline
\end{tabular}

knockout (CKO), Ywhah CKO, the oocyte-specific double CKO for Ywhae and Ywhah, and an oocyte from a female in which the Ppp1CC gene is globally inactivated (see Methods for details on the generation of these animals). The mean FPKM (with standard deviation) for each gene product is indicated utilizing all values except those in parentheses (CKO oocytes). Ensembl transcript IDs (mouse version GRCM38.p6): Ywhah, ENSMUST00000019109; Ywhae, ENSMUST00000067664; Ywhaq, ENSMUST00000135088; Ywhaz, ENSMUST00000022894; Ywhab, ENSMUST0000001 8470; Ywhag, ENSMUST00000055808; Sfn, ENSMUSG000 00047281.

\section{YWHAH and YWHAE protein distribution in the mouse oocyte}

A previous study determined that the distribution of YWHA isoforms in the cytoplasm and in the nucleus varied, depending on the isoform [42]. Because YWHA proteins are thought to sequester CDC25B in the cytoplasm of immature, prophase I-arrested oocytes, we investigated the distribution of two isoforms of interest, YWHAH and YWHAE by an alternative approach. We designed mRNA constructs that, after mRNA injection and expression in mouse oocytes, produced fluorescently labeled proteins, mCherry-YWHAH and EGFP-YWHAE. Oocytes expressed both fluorescent proteins very efficiently which, for each isoform, was primarily in the cytoplasm and much less so in the nucleus (Fig. 2a, b).

Expression of mCherry-YWHAH and EGFP-YWHAE following co-injection of both mRNAs indicates that these two proteins co-localize to some extent as there was spatial overlap of signal from the two separate emission wavelengths. The emission spectra of these two fluorescent probes display a clear separation of the peak excitation and emission wavelengths, thus there is very low crosstalk between the two excitation/emission channels. In addition, we use sequential confocal scanning to prevent overlap of excitation and emission wavelengths. Digitally combining the two images from sequential scans recording emissions from mCherry-YWHAH and EGFP-YWHAE reveals a similar distribution of the two fluorescence signals throughout the oocyte (Fig. 2c).
Further analysis, in the form of a scatter plot and analysis of pixel values along with determination of Pearson's correlation coefficient revealed some colocalization. In Pearson's correlation, the average pixel intensity values are subtracted from the original intensity values, so the value of this coefficient ranges from -1 to 1 , with a value of -1 representing a total lack of overlap between pixels from the images, and a value of 1 indicating perfect image correspondence. Analysis of the optical image of Cell 2 in Fig. 2c, for example, revealed an average of Pearson's correlation coefficient, $r$, over three regions of interest was 0.31 indicating a considerable degree of colocalization.

\section{CDC25B expression in the oocyte}

Immunofluorescence confocal imaging reveals that CDC25B is distributed throughout the prophase Iarrested oocyte cytoplasm and some CDC25B is also present within the nucleus (Fig. 3a). During the initial stage of oocyte maturation, CDC25B accumulates in the nucleus and by $2 \mathrm{~h}$ after release from meiotic arrest, the concentration of CDC25B is much greater in the region where the nucleus had undergone GVBD. In all oocytes studied at each time point, the identical distribution of CDC25B was noted. Minimal background staining was observed in control oocytes processed simultaneously and imaged at the same confocal settings, but without the primary antibody (Fig. 3a).

\section{In situ proximity ligation assays (PLA) reveal interaction of CDC25B with all isoforms of YWHA in oocytes and eggs}

To determine the possible interactions between each of the YWHA isoforms and CDC25B, we conducted a series of in situ proximity ligation assays (PLA) that identify interactions of two proteins at the molecular level by fluorescent detection probes. The PLA method has been used successfully to detect protein-protein interactions at the single molecule level directly in cells, and to visualize the actual intracellular sites of the interactions in different types of cells and tissues [52-55]. The PLA assay revealed interactions of all seven YWHA 
A

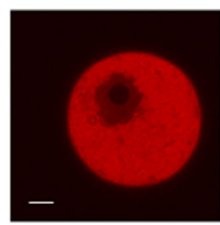

Expression of YWHAH
$\mathrm{B}$

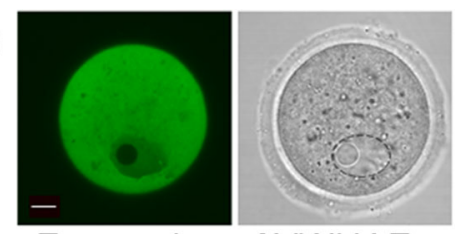

Expression of YWHAE

\section{Simultaneous Expression}

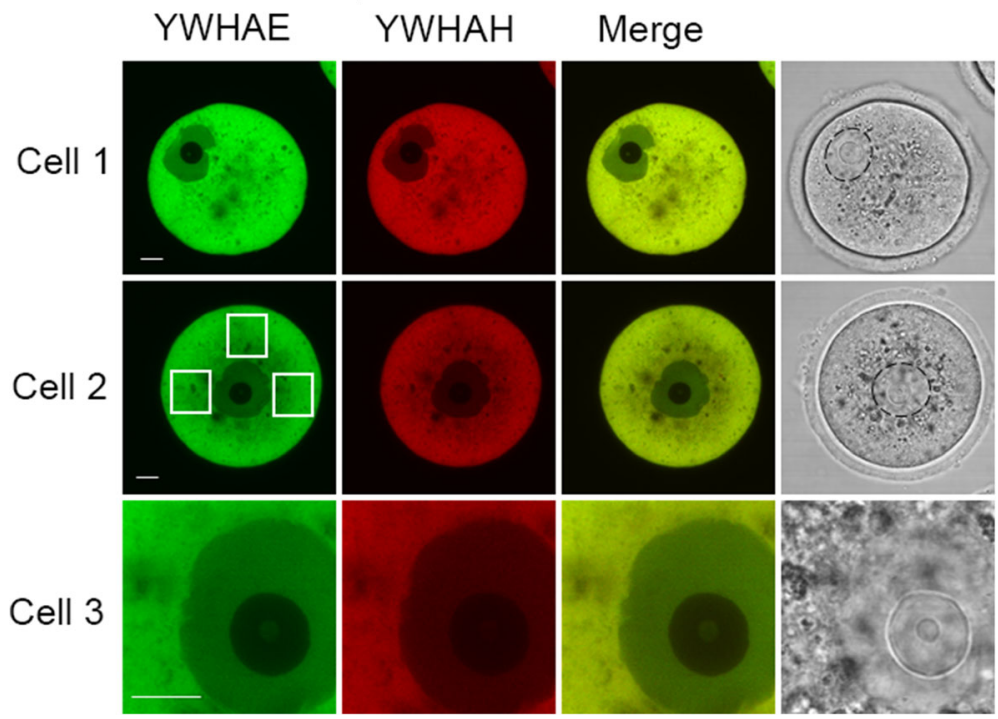

Fig. 2 Expression of fluorescently-tagged YWHAH and YWHAE in mouse oocytes. Immature oocytes from wild type ICR(CD-1) mice were microinjected with mCherry-YWHAH (a) or EGFP-YWHAE mRNA (b). The corresponding brightfield images are shown at the right and the oocyte nucleus is outlined with a dashed black line. The images are representative of results from 16 different oocytes expressing mCherry-YWHAH from five different experiments and 12 oocytes expressing EGFP-YWHAE from three different experiments. c Representative images of three oocytes simultaneously injected with mCherry-YWHAH and EGFP-YWHAE mRNA. Both isoforms are expressed in the same cell and the merged emission channels suggests a very similar distribution for both isoforms. The white squares shown in Cell 2 are the regions of interest used to determine the average Pearson's correlation coefficient for this cell (see Results). The nucleus was imaged at higher magnification in Cell 3. There is a clear distinction between the cytoplasm and the nucleus, with the nucleus displaying less fluorescence than the cytoplasm and the nucleolus

displaying little fluorescence. YWHAH and YWHAE are primarily cytoplasmic in an immature oocyte. All of seven other injected cells were similar. The scale bars represent $10 \mu \mathrm{m}$

protein isoforms with $\mathrm{CDC} 25 \mathrm{~B}$ within mouse oocytes and eggs using primary antibodies directed at each of the YWHA isoforms and CDC25B. Representative equatorial as well as compressed Z-stack images of oocytes and eggs from PLA assays are provided in Fig. 3b. Interactions are visible as fluorescent spots in a single equatorial scan in most cases. Each cell was scanned at $3 \mu \mathrm{m}$ intervals throughout the cell. The abundance of interaction sites is visualized when these scans are compressed into one image (compressed $\mathrm{Z}$ in Fig. $3 \mathrm{~b}$ ). It should be noted that the PLA method does not show the complete distribution of all $\mathrm{CDC} 25 \mathrm{~B}$ and YWHA proteins as would be shown in conventional immunofluorescence, but does show specific protein-protein interactions when a number of criteria have been met that include binding of the two primary antibodies to the target proteins, binding of secondary probes, ligation, amplification and hybridization of fluorescent detection probes. The PLA technique is sensitive, specific, and provides a high signal to noise ratio because the signal is amplified, and close proximity of the target proteins is required (<40 nm critical distance). Each of these steps is concentration- and time-dependent. The number of fluorescent spots represents only a portion of the protein-protein interactions. However, this method clearly provides more information about direct protein-protein interactions than simple colocalization studies with immunofluorescence microscopy. It is not possible to compare the results (the number of interaction sites, for example) among the different YWHA isoforms because of differences in primary antibody binding affinities.

No control oocytes or eggs, treated simultaneously and under identical conditions, incubated either with no primary antibodies (Fig. 3b, control), or with goat antiCDC25B primary antibodies alone, or with rabbit antiYWHA primary antibodies alone, displayed any PLA 


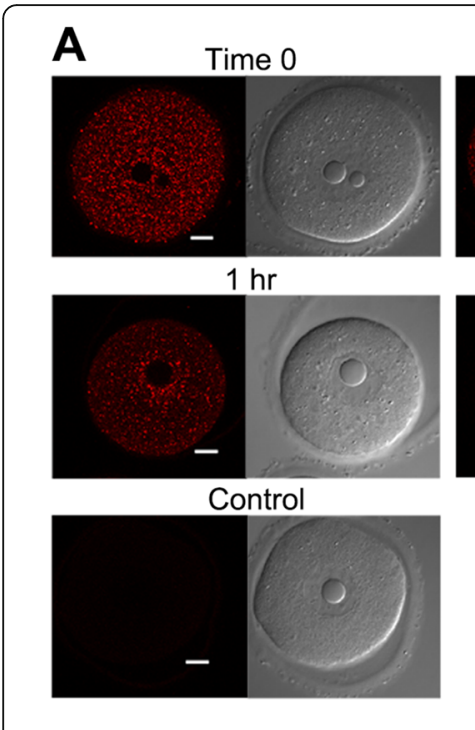

Equatorial Compressed Z Brightfield

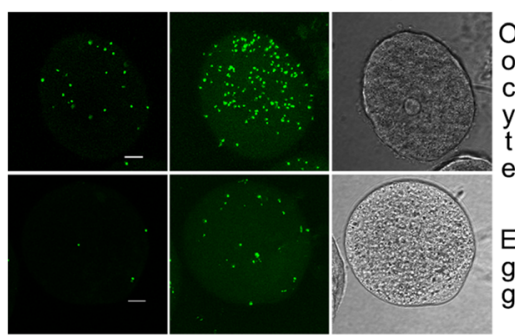

YWHAG + CDC25B

Equatorial Compressed Z Brightfield

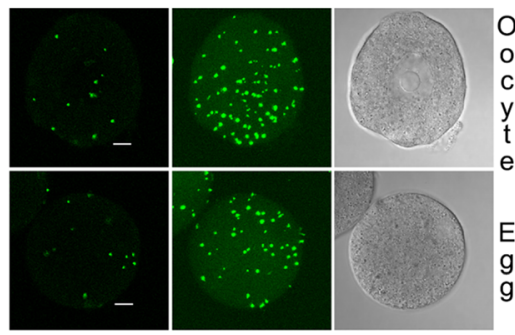

$\mathrm{SFN}+\mathrm{CDC} 25 \mathrm{~B}$

Equatorial Compressed $Z$ Brightfield

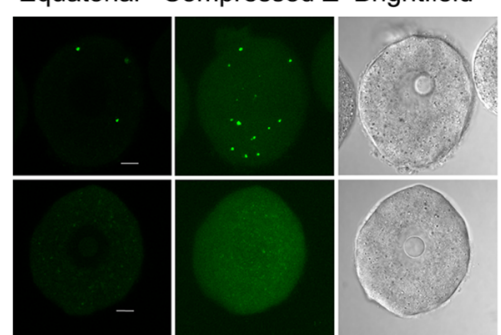

Rabbit anti-CDC25B + Goat anti-CDC25B
$0.5 \mathrm{hr}$

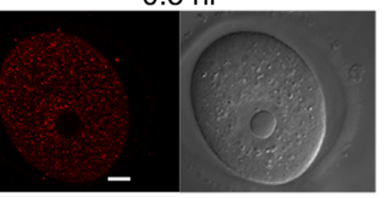

$2 \mathrm{hr}$

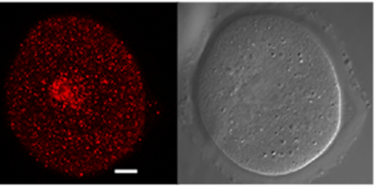

CDC25B localization during germinal vesicle breakdown (rabbit anti-CDC25B)
B Proximity Ligation Assays

Interactions of YWHA isoforms with CDC25B in oocytes and eggs

Equatorial Compressed Z Brightfield

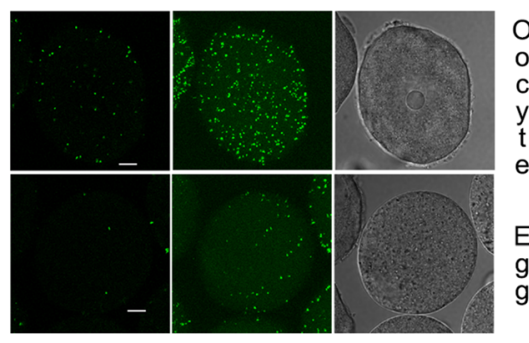

YWHAB + CDC25B
Equatorial Compressed Z Brightfield

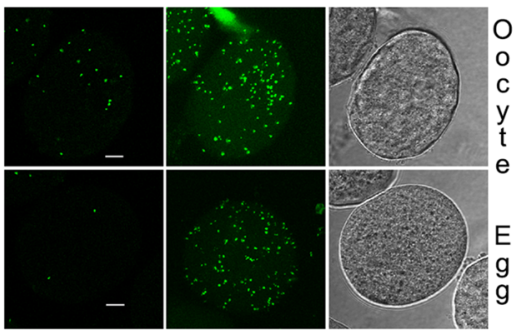

YWHAH + CDC25B

Equatorial Compressed Z Brightfield

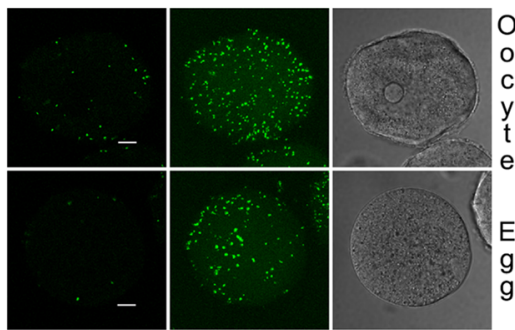

YWHAZ + CDC25B

Equatorial Compressed Z Brightfield

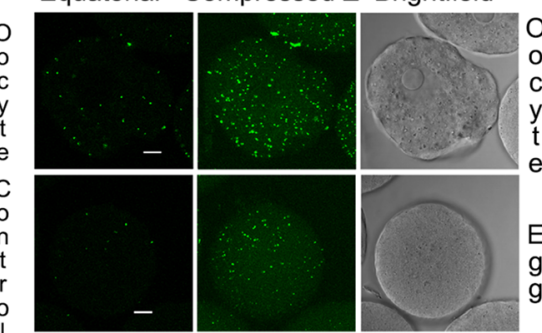

Rabbit anti-pSer149 CDC25B + Goat anti-CDC25B
Equatorial Compressed Z Brightfield

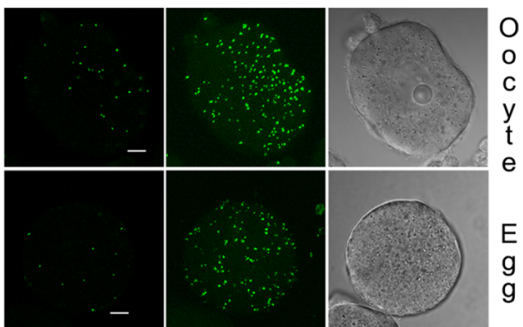

YWHAE + CDC25B

Equatorial Compressed Z Brightfield

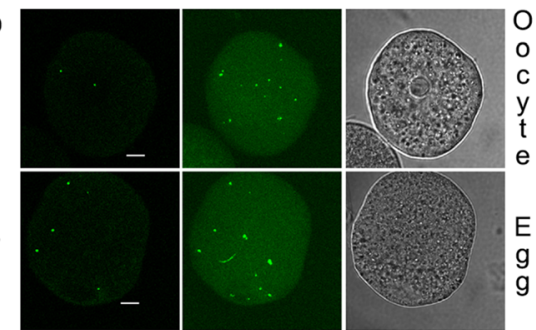

YHWAQ + CDC25B

Equatorial Compressed Z Brightfield

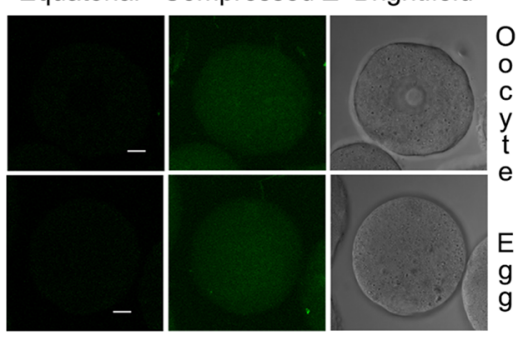

Control

Fig. 3 (See legend on next page.) 
(See figure on previous page.)

Fig. 3 CDC25B distribution during oocyte maturation and interactions with YWHA proteins demonstrated by proximity ligation assays in oocytes and eggs. a Paired confocal images of equatorial sections through oocytes (left: immunofluorescence; right: brightfield) with rabbit anti-CDC25B. CDC25B is present thorught the oocyte and accumulates in the region of the nucleus across a two-hour time course during in vitro maturation of mouse oocytes. Control oocytes processed simultaneously in absence of the primary antibody showed minimal background fluorescence. These images are representative of two experiments that examined 6-12 cells at each time point. b Representative images of oocytes and eggs showing proximity ligation reaction spots that indicate interaction of YWHA protein isoforms with CDC25B at the molecular level. Each reaction spot represents a protein-protien interacton between a CDC25B and a YWHA protein (see Methods for details). Except for the lower left images, the upper panel is an oocyte and the lower panel is an egg, each imaged with confocal fluorescence microscopy. The equatorial scan is a single scan and the compressed $\mathrm{Z}$ is obtained from combining consecutive cross-sectional images throughout each cell taken at $3 \mu \mathrm{m}$ intervals. The corresponding brightfield image is included. The lower two left panels are representative of the experiment using PLA with different primary antibodies against CDC25B directed at different sites on the protien. Binding to the same protein is indicated by PLA spots (rabbit anti-CDC25B and goat anti-CDC25B; rabbit anti-pSer149 CDC25B and goat anti-CDC25B). No reaction spots are observed in the control (oocytes and eggs processed in absence of the primary antibodies). The images shown are representative of two experiments (oocytes and eggs from four animals) with similar results for a total of 7-10 oocytes and a total of 6-11 eggs for each condition and controls. Scale bars for all images represent $10 \mu \mathrm{m}$

reaction spot. Background fluorescence from unbound fluorescent detection probes was minimal. To confirm the effectiveness of the PLA method, we processed oocytes and eggs for PLA using the goat anti-CDC25B with two different antibodies to $\mathrm{CDC} 25 \mathrm{~B}$ generated against different isotopes on the same protein (a general rabbit antibody against $\mathrm{CDC} 25 \mathrm{~B}$ and a rabbit antibody against p-Ser 149 CDC25B). Detection of the PLA reaction spots with antibodies bound to the same protein provides evidence for the effectiveness of the PLA method as the primary anitbodies should be well within $40 \mathrm{~nm}$ of each other to enable secondary probe DNA ligation and amplification. With these two antibodies, in situ PLA reaction spots were detected in all oocytes examined (a representative exmple is shown in Fig. 3b).

\section{FRET analysis indicates close interaction of YWHAH with CDC25B}

We utilized fluorescently tagged YWHAH and CDC25B to further examine possible interaction between these two proteins. Messenger RNA for mCherry-YWHAH and EGFP-CDC25B was introduced by microinjection into oocytes and, following overnight incubation, expression of the proteins was analyzed by confocal microscopy and Förster Resonance Energy Transfer (FRET). Cells microinjected with only donor (EGFP-CDC25B) mRNA or only acceptor (mCherry-YWHAH) mRNA were imaged, along with the FRET samples co-injected with messages for both proteins. Under normal conditions, EGFP is excited by blue light $(488 \mathrm{~nm})$ and emits green fluorescence $(507$ $\mathrm{nm})$. However, during FRET by sensitized emission, the green emission would transfer some energy to excite the mCherry fluorophores if they are within the Förster distance $(5.1 \mathrm{~nm})$ and red fluorescence $(610 \mathrm{~nm})$ will be emitted.

FRET efficiency was measured in three different regions of interest in the cytoplasm for each oocyte and average of these measurements was determined (Fig. 4). The range of FRET efficiency ranges from 64 to $82 \%$
( $n=12)$, averaging $73 \%$ for all cells. This strong FRET efficiency suggests a close interaction between YWHAH and $\mathrm{CDC} 25 \mathrm{~B}$ protein, which is consistent with the Duolink analyses. We have not examined other isoforms by FRET interactions but might expect a similar result. In comparison, we also examined the interaction of mCherryYWHAH and EGFP-YWHAE proteins (Fig. 4). The range of FRET efficiency ranges from 25 to $27 \%(n=5)$, averaging

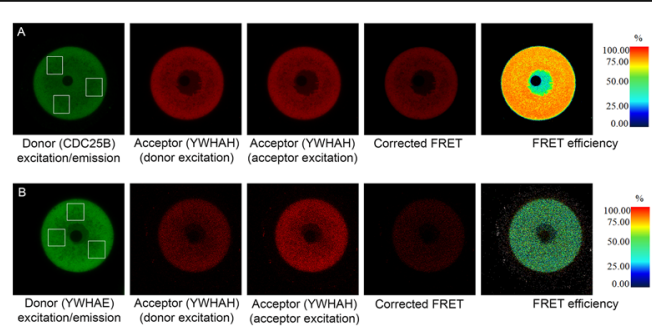

Fig. 4 FRET analysis of interaction of YWHAH with CDC25B and YWHAH with YWHAE. a ICR(CD1) oocytes were co-injected with mCherry-YWHAH and EGFP-CDC25mRNA. Expression of EGFPCDC25B protein provides the donor fluorescence (green) in the FRET analyses. The mCherry-YWHAH serves as the acceptor fluorescent probe (red). Images show the donor emission with donor excitation $(488 \mathrm{~nm})$, the acceptor emission with donor excitation, and the acceptor emission with acceptor excitation $(543 \mathrm{~nm})$, and the corrected FRET image. Data from three regions of interest (shown by white boxes) were used to calculate the FRET efficiency, which, in this cell averaged $72 \%$, and is visually represented in the heat map at the right. The figure is representative of 12 oocytes collected from three different females in three experiments. $\mathbf{b}$ ICR(CD1) oocytes were co-injected with mCherry-YWHAH and EGFP-YWHAE. EGFPYWHAE protein provides the donor fluorescence (green) in the FRET analyses. The mCherry-YWHAH serves as the acceptor fluorescent probe (red). Images show the donor emission with donor excitation $(488 \mathrm{~nm})$, the acceptor emission with donor excitation, and the acceptor emission with acceptor excitation ( $543 \mathrm{~nm}$ ), and the corrected FRET image. Data from three regions of interest (show by white boxes) was used to calculate the FRET efficiency, which in this cell averaged $27 \%$, and is visually represented in the heat map at the right. The figure is representative of five oocytes examined in two experiments 
22.5\% for all cells. This is a fairly strong interaction and might be suggestive of heterodimer formation between YWHAE and YWHAH, which would need to be examined further.

\section{Microinjection of oocytes with the YWHA-inhibitory peptide R18 promotes oocyte maturation}

As detailed in the Introduction, it is thought that CDC25B is phosphorylated and that CDC25B is held in an inactive state by being bound to YWHA proteins. Therefore, to demonstrate directly in mouse oocytes that YWHA/CDC25B interaction is required for meiotic arrest, we performed a series of experiments to disrupt this interaction, with the hypothesis that preventing the interaction of CDC25B with YWHA proteins would lead to oocyte maturation by rendering the $\mathrm{CDC} 25 \mathrm{~B}$ free to dephosphorylate CDK1 and activate MPF.

In a preliminary experiment to examine YWHA protein function, we injected oocytes with the synthetic YWHA-inhibitory peptide R18. For these experiments, we determined the threshold or critical concentration of dbcAMP, just enough to maintain prophase I arrest in at least $75 \%$ of oocytes cultured overnight, to be $0.05 \mathrm{mg} /$ $\mathrm{mL}$. Oocyte maturation experiments in this concentration of dbcAMP permitted us to examine treatments that could promote maturation compared to control cells in which meiotic arrest is maintained but is not dominated by the activation of PKA by dbcAMP. Microinjection of $0.5 \mathrm{mg} / \mathrm{mL}$ R18 into oocytes, followed by overnight incubation in media containing $0.05 \mathrm{mg} / \mathrm{mL}$ dbcAMP, promoted release from meiotic arrest and GVBD in a larger number of cells compared to uninjected control oocytes or control oocytes injected with deionized water. Ten of 15 (67\%) of oocytes underwent GVBD following R-18 injection, while only 4 of $16(25 \%)$ did so when injected with deionized water, and only 5 of 18 (28\%) control uninjected oocytes underwent GVBD (Fig. 5a). Examination of the data in the R18 study using Fisher's exact test and pairwise comparison of the percentage of GVBD in the control uninjected cells and control water-injected cells revealed no significant difference between those groups $(P=>0.999)$. Pairwise comparison of the R18-injected cells to the control water-injected cells revealed a significant difference $(P<0.05)$.

The effectiveness of R18 inhibition is certainly concentration-dependent; however, the injection of a more concentrated peptide solution was not possible. In addition, of course, some residual PKA, kept active by the $0.05 \mathrm{mg} / \mathrm{mL}$ dbcAMP, may affect CDC25B as well as other proteins involved in cell cycle control. Nevertheless, the experiment suggests that inhibiting some interactions of YWHA with its binding partners, including $\mathrm{CDC} 25 \mathrm{~B}$, shifts the balance toward release from the meiotic arrest. To further investigate this possibility, we chose the following more specific approach of reducing YWHA protein synthesis rather than inhibiting its action.
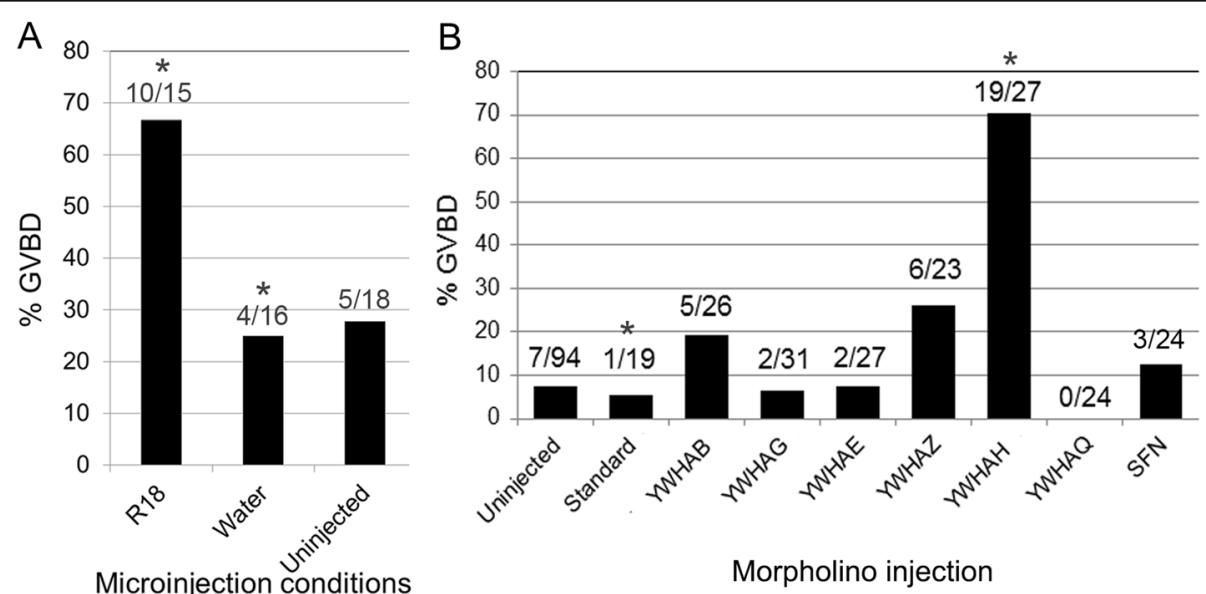

Fig. 5 Injection of the YWHA-inhibitory peptide and Ywha mRNA antisense morpholinos against mRNA for each Ywha isoform. For each injection condition and the uninjected controls in this series of experiments, the number of cells with GVBD is represented as a percent of the total number of cells studied (indicated at the top the corresponding bar). See the Methods section for experimental methods. a Percent germinal vesicle breakdown (GVBD) in mouse oocytes injected with the YWHA-inhibitory peptide R18, water or uninjected. The data is combined from two repeated experiments. Fisher's exact test and pairwise comparison of the percentage of GVBD in the control uninjected cells and control waterinjected cells revealed no significant difference between those groups, while a significantly greater percentage of GVBD was noted for oocytes injected with R18 compared to control water-injected cells (* in A). b Percent GVBD in oocytes injected with antisense morpholinos against each of the seven mammalian Ywha mRNA isoforms as well as the standard nonsense moprholino that was designed to have no effect. The data is combined from two repeated experiments. A significantly greater percentage of GVBD was noted for oocytes injected with morpholino targeting Ywhah mRNA compared to control non-sense morpholino $\left(^{*}\right.$ in B) 


\section{Knockdown of YWHA isoforms with antisense morpholinos}

In a series of experiments for each YWHA isoform, GVintact oocytes arrested in prophase I were microinjected with a translation-blocking morpholino oligonucleotide (MO) against mRNA for each of the Ywha isoforms at a final intracellular concentration of $0.1 \mathrm{mM}$. The oocytes were injected with MOs and then held for $24 \mathrm{~h}$ in prophase arrest with media containing $0.1 \mathrm{mg} / \mathrm{mL}$ dbcAMP to permit a reduction of the existing YWHA protein. The oocytes were then transferred into media containing 0.05 $\mathrm{mg} / \mathrm{mL}$ dbcAMP, a threshold concentration just sufficient to maintain prophase I arrest, incubated for $14-16 \mathrm{~h}$, and then scored for GVBD (see Fig. 5b). A greater number (70\%) of oocytes injected with MO against $Y$ whah mRNA were found to undergo GVBD, in contrast with oocytes injected with MOs targeting other Ywha mRNA isoforms. Under identical conditions in this series of experiments, GVBD in control, uninjected oocytes was only about $7.5 \%$ and only about $5 \%$ for oocytes injected with a standard, nonsense morpholino oligonucleotide known to be incapable of binding to any of the Ywha mRNAs. Statistical analysis of $2 \times 2$ contingency tables using Fisher's exact test indicated no significance difference in percent GVBD between the uninjected cells and the cells injected with standard nonsense morpholino $(P>0.999)$. Pairwise comparison of each of the $Y w h a$ isoform morpholino injection conditions with the nonsense morpholino control revealed no significant differences in percent GVBD between the control and the experimental group $(P>0.05)$, with the exception of $Y$ whah $(P<0.0001)$. These results suggested that among the seven mammalian isoforms of YWHA proteins, all of which were found to bind to CDC25B, YWHAH may be important for maintaining the prophase I arrest of mouse oocytes through interaction with CDC25B or other proteins. The experimental analysis is, however, limited since the extent of mRNA inactivation in the knockdown experiments is likely to be variable. Moreover, residual activation of PKA in "threshold" concentrations of dbcAMP may be sufficient to alter oocyte maturation in this experimental situation.

\section{Ywhah or Ywhae inactivation by oocyte-specific and global knockouts}

To definitively characterize the role of the YWHAH protein isoform, we generated mice with an inactive $Y$ whah gene using the LoxP-Cre system. This permitted generation of animals in which the Ywhah gene is inactivated specifically in oocytes or globally in all cells of a female mouse. We also generated oocyte-specific and global Ywhae knockout mice, since the YWHAE protein had been suggested by other investigators to play a role in oocyte maturation. The production of these genetically modified mice is described in the Methods section. In brief, oocyte-specific gene inactivation was generated in animals expressing Lox-P sites with ZP3-Cre, a Cre recombinase driven by the zona pellucida protein 3 (ZP3) promoter and which is expressed only in oocytes beginning in primary follicles and maintaining expression in preantral follicles [56]. ACTB-Cre mice were used to generate a global knockout. ACTB-Cre is driven by the human beta actin gene promoter and is expressed in all cells of the embryo by the blastocyst stage [57]. It is expected then, to act on LoxP constructs in early cells of the blastocyst to generate embryos and adults in which gene function is altered in all cells.

\section{Oocyte-specific Ywhah or Ywhae gene inactivation does not alter in vivo breeding}

Female mice with oocyte-specific knockout of Ywhah or Ywhae were mated with wild-type male mice. The females were genotyped to confirm the knockout condition and, when conditions permitted, absence of the gene was also confirmed by Western blot. In vivo breeding indicated that reproductive capacity is not greatly altered with oocyte-specific inactivation of either gene when breeding of pairs were maintained for 2 to 10 months. It should be noted that variation in litter number is common and depends on the characteristics of the female and the male in the breeding pairs and other factors. Females with the oocyte-specific inactivation of Ywhah or Ywhae are fertile and litter sizes fall in the normal range when compared to litter sizes of females in which Ywhah or Ywhae genes are not inactivated (mice containing only the floxed alleles for Ywhah or Ywhae or female mice containing only the transgene for the ZP3 or ACTB Cre recombinase with no modification of the Ywha genes). Breeding data of individual females are summarized in Fig. 6.

The litter sizes of females with global inactivation of $Y$ whah in all tissues, including the ovary, are like those of the oocyte-specific knockout animals and are similar to the litter sizes of females in which the gene is not inactivated. In contrast, no offspring are produced when the gene for Ywhae is inactivated in all tissues, including the ovary (Fig. 6a, global Ywhae). As described below, oocytes from both oocyte-specific and global Ywhae knockout mice appear to mature normally. In addition, eggs collected from females with oocyte-specific Ywhae inactivation can be fertilized in vitro to produce two-cell embryos without adverse effect on the first meiotic division. Inhibition of in vivo breeding in the global Ywhae, but not the oocytespecific, knockout mouse suggests that YWHAE may be required in somatic cells in other tissues affecting reproductive potential. 


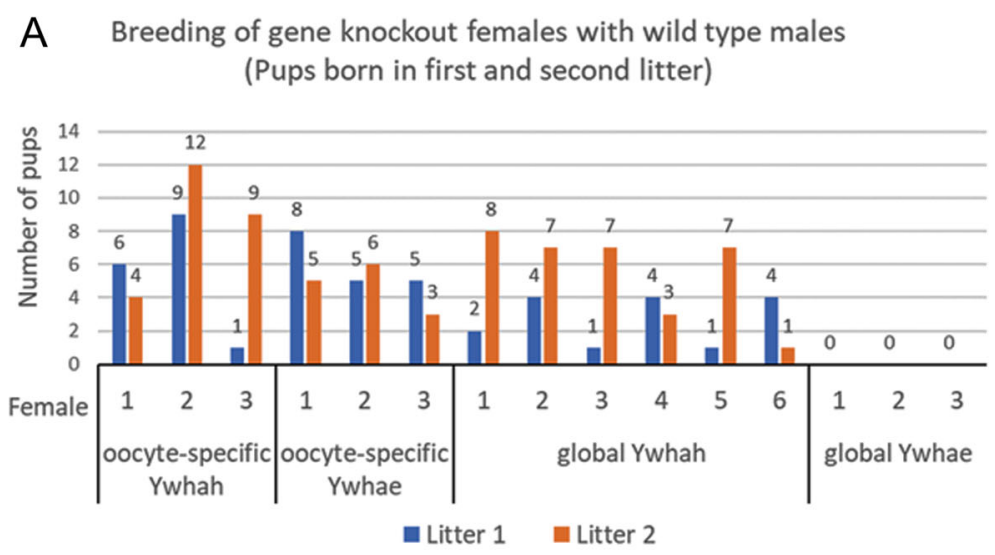

B Breeding of female mice with no gene knockout

(Pups born over 2 litters)

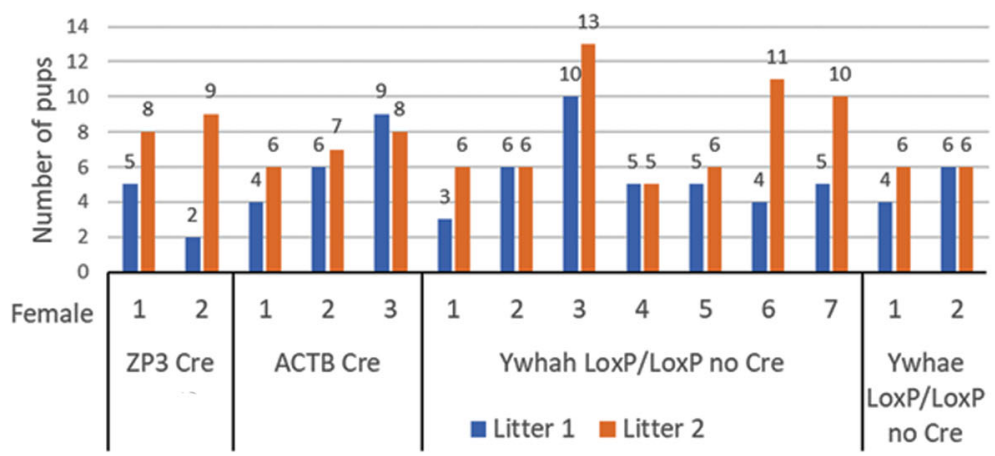

Fig. 6 Breeding of Ywhah and Ywhae oocyte-specific and global gene knockout mice with wild-type males. The number of pups for each female of a given geneotype is indicated for the first two litters. In vivo breding illustrates the range of offspring number in mice of different females mated with different wild-type males. Here, the number of pups produced by females with oocyte-specific inactivation of Ywhah or Ywhae and global inactivation of Ywhah (a) falls within the normal range of litter sizes of mice without gene inactivation (here mice containing ZP3 or ACTB Cre, and mice with floxed Ywhah or Ywhae gene (LoxP/LoxP) and no Cre (b). However, females with global inactivation of Ywhae did not produce pups (last group in (a), see Results and Discussion)

\section{Oocyte-specific or global Ywhah or Ywhae gene inactivation does not alter oogenesis or in vitro oocyte maturation}

The in vivo breeding data suggests that normal offspring are produced despite oocyte-specific inactivation of the genes for Ywhah or Ywhae. To further examine the characteristics of oocytes from these knockout animals we collected oocytes as usual and matured them in vitro to determine if there was any difference in the number of germinal vesicle-intact oocytes collected or any difference the extent of maturation in vitro. Absence of YWHAH or YWHAE protein in oocytes does not appear to affect the number of germinal vesicle-intact oocytes isolated from females primed with eCG and cultured in 3-Isobutyl-1-methylxanthine (IBMX) to prevent spontaneous maturation. The oocytes were of typical size and normal morphology. The extent of in vitro maturation was not altered when oocytes were allowed to mature in media without IBMX. As shown in Fig. 7, the percent of oocytes from a given female that mature is somewhat variable, typically ranging from 75 to $100 \%$. For each female, oocytes cultured overnight in IBMX-free media were classified as having intact GVs or having undergone GVBD indicating oocyte maturation, therefore a non-parametric statistical analysis was done using Fisher's exact test $(2 \times 2$ contingency table $)$ in which the data for all females for a given group was combined and compared to the data of in vitro maturation of oocytes from wild-type females combined. A two-tailed $P$ value of less than 0.05 is considered to indicate a significant difference. Comparing the four knockout conditions to the wild-type data, all pairwise $P$ values are greater than 0.05 (oocyte-specific Ywhah, $P=0.34$; oocyte-specific Ywhae, $P=0.87$; global Ywhah, $P=0.08$; global $Y$ whae, $P=0.23)$. When data from the double knockout condition (oocyte-specific Ywhah and Ywhae) is compared to the wild-type data, the pairwise $\mathrm{P}$ value equals 0.05 . However, for these three females, maturation of oocytes is mostly normal with the percent of maturation ranging from 73 to $88 \%$ (Fig. 7c). Comparing the two heterozygous 


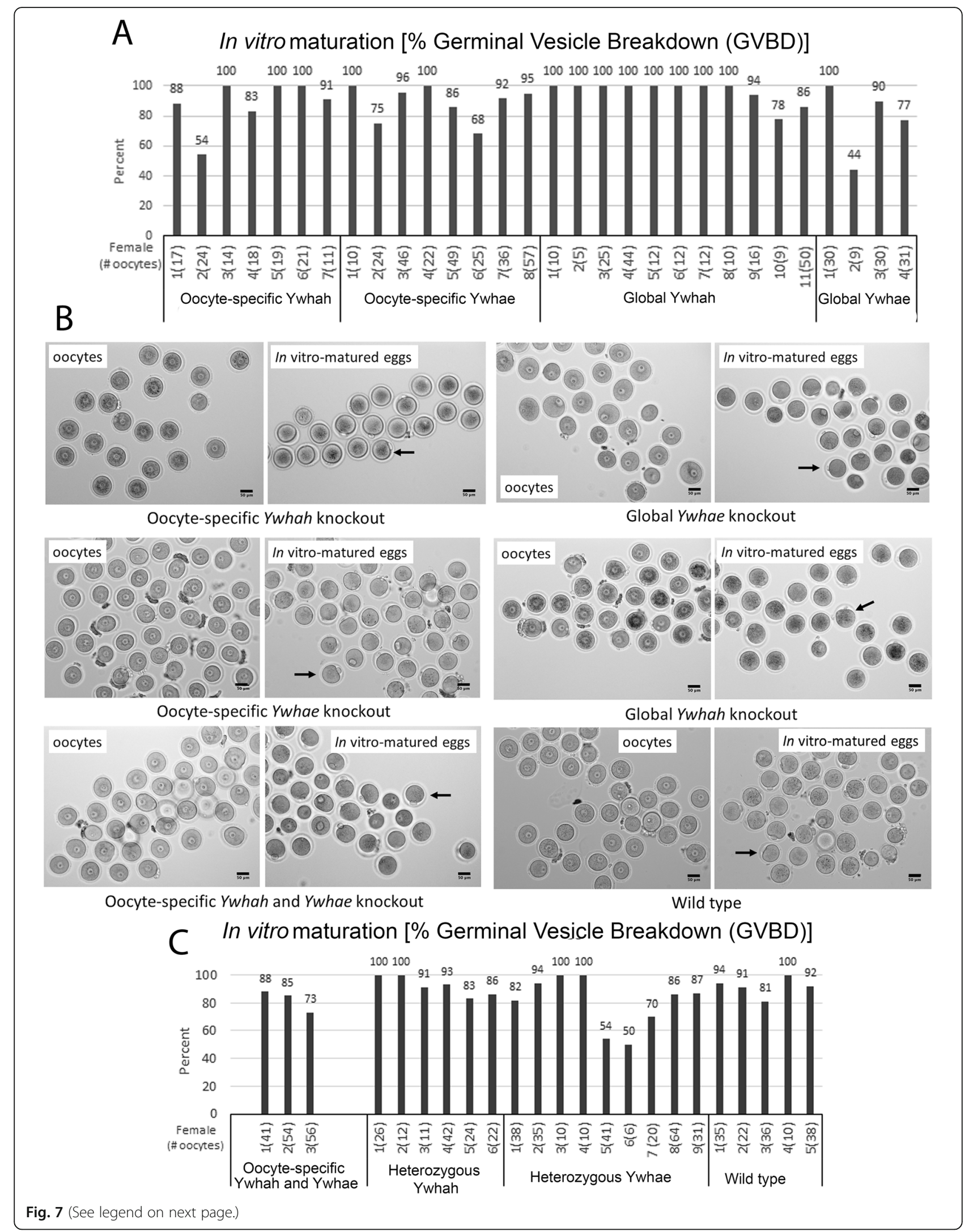


(See figure on previous page.)

Fig. 7 a In vitro maturation of oocytes from Ywhah and Ywhae oocyte-specific and global knockout females. For each female of a given genotype, the total number of oocytes examined is indicated in parentheses and the percent of those oocytes that underwent germinal vesicle breakdown (GVBD) is indicated in the bar graph. The extent of oocyte maturation, as indicated by GVBD, is high in females of all genotypes in which Ywhah or Ywhae is inactivated specifically in the oocyte or globally. $\mathbf{b}$ Representative images of oocytes collected from knockout females and the corresponding images of the mature eggs the following day after in vitro maturation of oocytes from knockout females and wild-type females. Oocytes from females of all genotypes appear normal with intact germinal vesicles. Arrows indicate the first polar body of some eggs, which is not always visible because of the orientaion of the egg. Scale bars represent $50 \mu \mathrm{m}$. $\mathbf{c}$ In vitro maturation of oocytes from females in which both the Ywhah and Ywhae genes were inactivated in the oocyte, oocytes from females in which one allele of Ywhah or Ywhae was inactivated (hetetrozygous), or oocytes from wild-type females

conditions to the wild-type data, the pairwise $\mathrm{P}$ values were greater than 0.5 (heterozygous Ywhahe, $P=0.68$; heterozygous Ywhae, $P=0.015)$. This suggests that the absence of one allele has no effect on oocyte maturation.

\section{In vitro fertilization of eggs from mice with oocyte- specific inactivation of Ywhae is normal}

To further examine the role of Ywhae in mouse oocytes we examined the fertilization potential and early development of eggs collected by superovulation from five different oocyte-specific Ywhae knockout females (Fig. 8). Thirty-five to $56 \%$ of the eggs from a given Ywhae knockout female were fertilized and developed normally to the two-cell stage, which is comparable to typical in vitro fertilization rates of wild-type mice (data from two are shown in Fig. 8). Fertilized eggs from two Ywhae knockout females maintained in culture and developed to the morula and/or blastocyst stage.

\section{Discussion}

\section{Multiple YWHA isoforms are transcribed in mouse oocytes and eggs}

All seven Ywha isoform transcripts were detected in oocytes from ICR(CD-1) mice by PCR using isoformspecific primers. $S f n$ transcript, while identified in oocytes from ICR(CD-1) mice, was not detected in the inbred C57BL/6 J strain. Single cell mRNA sequencing also revealed transcripts for all seven isoforms in $\mathrm{ICR}(\mathrm{CD}-1)$ mice and in various knockout models. In contrast, one report indicates that only $Y w h a b$ and Ywhae transcripts could be detected in mouse oocytes [43]. However, several other published reports on the presence of Ywha messages in the mouse egg agree with our results. Notably, in an expression profiling study of mature mouse eggs [44], six Ywha isoforms were detected ( $S f n$ was not listed in this report). In a different analysis of maternal mRNA expression in mature eggs [58] Ywhab, Ywhag, Ywhah, Ywhaq and $Y w h a z$ were noted (others were not mentioned in this report which examined only large changes in expression profiles of late one cell embryos compared to eggs). Of additional interest are two reports on human eggs clearly indicating the all seven isoforms of
Ywha messages exist in the human egg [45, 46]. Taken together, our data on Ywha transcripts and protein expression, along with other published results indicates presence of transcripts and proteins of all seven YWHA isoforms in mouse and human oocytes and eggs. Therefore, it is prudent to consider all YWHA isoforms in any analysis of YWHA functional roles in oocyte maturation, fertilization and early embryonic development.

\section{Exogenously expressed YWHAH and YWHAE co-localize in mouse oocytes and are predominantly cytoplasmic}

The exogenous expression of fluorescently labeled YWHAH and YWHAE proteins revealed a distribution of these YWHA proteins like that previously observed by immunofluorescence and immunohistochemistry [42]. The two isoforms are found in similar locations as indicated by a relatively high Pearson's correlation and both isoforms are found primarily in the cytoplasm and not in the nucleus. It was also previously reported that YWHAE is primarily cytoplasmic in mouse oocytes [43].

\section{Interactions of YWHA isoforms with CDC25B in oocytes and eggs}

Using in situ Proximity Ligation Assays, we have been able to demonstrate that all seven mammalian isoforms of YWHA interact with CDC25B in both mouse oocytes and eggs. This data indicates that the associations of CDC25B with YWHA proteins may occur through interactions with multiple isoforms. It is necessary to examine all YWHA isoforms when examining the regulation of CDC25B. Some previous reports on oocyte and egg YWHA protein interaction with $\mathrm{CDC} 25 \mathrm{~B}$ have examined only several of the YWHA isoforms [43, 59]. We also note here, that by FRET analysis, that there is a strong interaction between exogenously expressed mouse YWHAH and CDC25B, that suggests binding between the two proteins. We might expect a similar result of FRET analysis in examination of the interaction of CDC25B with other YWHA isoforms.

As we report here for oocytes and eggs, it is known from studies in somatic cells that all seven isoforms bind to CDC25B; however, YWHAB, YWHAG, 


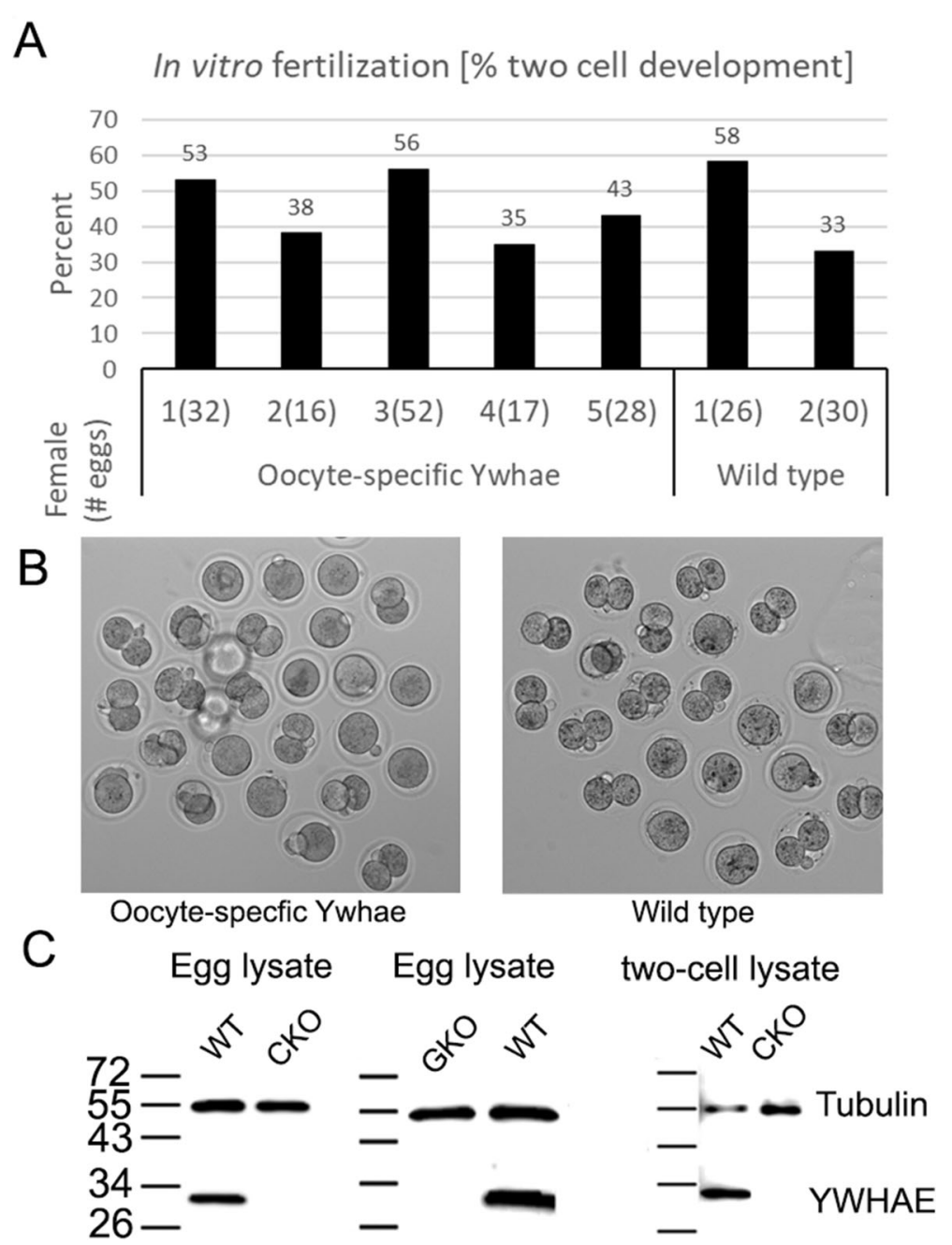

Fig. 8 In vitro fertilization of eggs from Ywhae knockout females. a For each of five different females with oocyte-specific knockout of Ywhae, the total number of eggs collected and inseminated is indicated in parentheses and the percent of those eggs that proceeded to the two-cell stage is indicated in the bar graph. Two representative examples of fertilization and percent of two cell development of wild-type eggs are shown. In two cases (females 4 and 5), fertilized eggs from Ywhae gene knockout females were continued in culture and developed to the morula and/or blastocyst stage. $\mathbf{b}$ Representative images of eggs or two-cell embryos following in vitro fertilization of eggs from oocyte-specific Ywhae knockout females or a wild-type female. c Representative Western blot of cell lysates of eggs collected from wild-type females, lysates of oocyte-specific knockout of Ywhae (conditional knockout or CKO), lysates of eggs collected from the global knockout of Ywhae (GKO), and lysates of two-cell embryos from fertilized wild-type eggs and from fertilized eggs of females with oocyte-specific knockout of Ywhae (conditional knockout or CKO). The blots were probed with antibodies for YWHAE or tubulin (loading control). YWHAE protein was not detected in the knockout eggs nor in the two-cell embryos

YWHAH and YWHAQ interact more strongly than YWHAE, YWHAZ and SFN [60]. Moreover, those that bind more strongly cause $\mathrm{CDC} 25 \mathrm{~B}$ to be exported form the nucleus. While all isoforms of YWHA are capable of binding, the binding of specific YWHA isoforms may affect the localization and function of CDC25B. In addition, it will be important to explore the nature of YWHA heterodimers in regulating maturation. We do not know if YWHA heterodimers form to bind to $\mathrm{CDC} 25 \mathrm{~B}$ or other target proteins in the oocyte.
YWHA proteins appear to be important in meiotic arrest of mouse oocytes

Inhibition of YWHA proteins by the inhibitory peptide R18 appears to promote maturation, even in the presence of a threshold concentration of dbcAMP. It has been proposed that YWHA proteins bind to CDC25B and sequester it in the cytoplasm, preventing the premature activation of oocyte maturation. The R18 peptide shares a common binding site on YWHA with other YWHA-binding partners, and peptide R18 competitively inhibits interactions between YWHA and its binding 
partners [61]; thus, R18 can displace proteins bound to YWHA. The interaction of R18 with YWHA does not depend on the YWHA isoform and the peptide does not require prior phosphorylation for binding. The utility of the R18 peptide has been demonstrated, for example, to show that YWHA is a critical regulator of anti-apoptotic signaling in various cells [62, 63], including cultured ovarian granulosa cells [64]. Introduction of R18 message in frog eggs produced defects in axial patterning and mesoderm specification [65]. Here, when mouse oocytes were microinjected with the synthetic YWHAinhibitory peptide R18 and incubated in presence of the threshold concentration of $0.05 \mathrm{mg} / \mathrm{mL}$ dbcAMP there was a $\sim 40 \%$ greater incidence of germinal vesicle breakdown compared to uninjected control oocytes or to control oocytes injected with sterile, deionized water. Thus, disruption of YWHA binding to target proteins promotes oocyte maturation.

We utilized isoform-specific morpholino-mediated knockdown experiments which indicated that meiotic arrest in mouse oocytes may be maintained by YWHAH since introduction of this morpholino, targeting Ywhah message, appears to be effective in promoting germinal vesicle breakdown in the presence of a threshold concentration of dbcAMP. It has been proposed by other investigators that YWHAE protein is responsible for maintaining prophase I arrest in mouse oocytes, since in one series of experiments, 36\% of oocytes underwent GVBD after injection of siRNA to knockdown YWHAE in the presence of dbcAMP [43]. However, injections of siRNA for the other six isoforms were not done by these researchers. We did not find strong evidence for a role of YWHAE in holding eggs in prophase arrest based on the morpholino experiments. Reliance on injection of R18 and inhibitory morpholinos or siRNA is insufficient to define the role of specific YWHA proteins. Introduction of R18 does not mean that all YWHA proteins are inhibited completely. Interference of mRNA by siRNAs or morpholinos does not mean that all protein synthesis is inhibited. By their nature, these are protein knockdown experiments. Moreover, analysis by these methods is complicated by the fact the dbcAMP is present. Multiple proteins are targeted for phosphorylation by PKA. Therefore, we utilized genetic knockout experiments to define the role of the two isoforms that might be important based on our work and others, YWHAH and YWHAE.

Oocyte-specific Ywhah or Ywhae gene inactivation does not alter in vivo breeding or in vitro oocyte maturation If meiotic arrest was solely and completely dependent on YWHAH or YWHAE binding to CDC25B, one might expect that elimination of either of these proteins could lead to premature oocyte maturation, since CDC25B would not be held in the cytoplasm in an inactive state in oocytes within the follicle. We found no evidence that oogenesis was altered when either YWHAH or YWHAE proteins or both were absent. Oocytes obtained from these animals after eCG priming had intact GVs, were normal in size and morphology, and there was no indication of premature meiosis I resumption. Oocytes from these animals underwent normal in vitro maturation. We previously noted that YWHAH may play an important role in meiotic spindle formation by employing antisense morpholino knockdown approaches [55]. The gene knockout experiments presented here suggest that, if YWHA proteins are required in spindle formation, other isoforms might substitute. It would be valuable to follow up on this line of research. Breeding and development of pups was normal in the absence of YWHAH or YWHAE in females with oocyte-specific knockout of these genes.

\section{Global inactivation of Ywhah gene does not alter in vivo breeding or in vitro oocyte maturation}

As with oocyte-specific $Y$ whah gene inactivation, we found no apparent difference in fertility, oogenesis or in vitro maturation of cells obtained from animals with global inactivation of the Ywhah gene compared to animals containing the gene. This suggests that YWHAH protein is not required in germ cells or in somatic cells for normal reproduction. We found no obvious abnormal phenotype in YWHAH knockout females. This indicates that YWHAH protein is not essential for female reproduction and early embryonic development and, given the importance of YWHA in many cellular events, other isoforms of YWHA might substitute. Normal morphology and presumably normal fertility in female YWHAH knockout mice have also been recently reported by other investigators who found that absence of YWHAH protein leads to deafness and hair cell degeneration [66].

\section{Global deletion of the Ywhae gene prevents breeding without affecting oogenesis, oocyte maturation or in vitro fertilization}

No offspring were produced by females when the Ywhae gene was inactivated in all tissues, including the ovary and oocytes. However, oocytes collected from these mice appear to mature normally in vitro. With germ-line deletion of Ywhae in a global knockout, mice die at birth due to cardiac malformations [48]. Deletion of Ywhae in oocytes is apparently compensated by introduction of the normal gene from sperm at fertilization, since apparently normal pups are produced in the oocyte-specific knockout of Ywhae, while in the female YWHAE protein may be required in somatic cells in other tissues of the female, for example in the uterus where implantation might be altered. This observation suggests an important 
role for YWHAE that will need to be examined. It has been reported that only Ywhae message is expressed in mouse eggs and that knockdown of Ywhae message by small interference RNA inhibits first mitosis in some percentage of fertilized mouse eggs [59]. We find that oocytes collected from females in which Ywhae is disrupted in oocytes undergo normal in vitro maturation, in vitro fertilization and early development to the 2-cell stage. Maternal expression of YWHAE protein does not appear to be required for the first mitotic division nor does absence of the protein interfere with the first mitosis.

\section{YWHA proteins in meiosis}

Given the central role of YWHA proteins in regulating the mitotic cell cycle and evidence for regulation of meiosis, additional work is needed to define the roles of the specific isoforms. All YWHA isoforms need examination. Other cell cycle control proteins, in addition to $\mathrm{CDC} 5 \mathrm{~B}$, will need to be investigated in more detail to complete the analysis of YWHA proteins in meiotic regulation. Certainly, a number of cell cycle control proteins interact with YWHA, reviewed in [67]. For example, it is known that YWHA proteins interact with Wee1 in frog egg extracts [68], in human somatic cells [27, 69] and with expressed mouse Wee1 protein [70, 71]. Further study will be needed to examine the interaction of YWHAH protein with the oocyte-specific WEE2, its activity and the phosphorylation of CDK1.

\section{Conclusions}

We find that multiple isoforms of YWHA protein are expressed in mouse oocytes and all seven isoforms appear to interact with CDC25B. While this work and other research suggests that YWHA proteins may bind to and regulate the activity of $\mathrm{CDC} 25 \mathrm{~B}$, as well as possibly additional proteins that regulate oocyte maturation, the oocyte-specific gene knockout experiments indicate that YWHAH and YWHAE proteins are not required for normal oogenesis, oocyte maturation and early embryonic development. The data suggest that one or several of the other YWHA isoforms may compensate for absence of YWHAH or YWHAE proteins within the oocyte, and this possibility should be explored. Global inactivation of $Y$ whah in female mice does not appear to alter oogenesis, oocyte maturation and early development, while global inactivation of Ywhae in female mice prevents breeding without affecting oogenesis, oocyte maturation or in vitro fertilization.

\section{Methods}

\section{Collection of oocytes and eggs}

All mice used in the present experiments were housed and used at Kent State University with the approval of the Kent State University Institutional Animal Care and Use Committee following the appropriate laws, guidelines and policies and performed in accordance with the $\mathrm{NIH}$ and National Research Council's publication, "Guide for Care and Use of Laboratory Animals". Tissues were only obtained from euthanized mice following the approved protocol. Animals were euthanized by $\mathrm{CO}_{2}$ inhalation (approximately $5 \mathrm{~min}$ in small container gassed with $\mathrm{CO}_{2}$ from a regulated tank of compressed $100 \% \mathrm{CO}_{2}$ ). This was followed by cervical dislocation to ensure death. Standard breeding and selection of specific genotypes also included euthanasia of some animals using this protocol. To obtain oocytes, female mice were injected with $5 \mathrm{IU}$ eCG to stimulate follicle growth and 44-48 $\mathrm{h}$ later, following euthanasia, the ovaries were removed and repeatedly punctured with a 26 -gauge needle to rupture follicles. Cumulus cell-enclosed oocytes were isolated, and the cumulus cells were removed by repeated pipetting though a small-bore pipette. Fullygrown oocytes with intact nuclei (germinal vesicles) were cultured in MEM $\alpha$ supplemented with pyruvate and an antibiotic/antimycotic, and containing $0.1 \mathrm{mg} / \mathrm{mL}$ dibutyryl cAMP (dbcAMP; Sigma-Aldrich) or $0.1 \mathrm{mg} / \mathrm{mL} 3$ Isobutyl-1-methylxanthine (IBMX; Sigma-Aldrich), each of which prevents cAMP breakdown and spontaneous oocyte maturation. Mature, metaphase II-arrested eggs were obtained from euthanized mice $13-14 \mathrm{~h}$ following superovulation by injection of 5 IU hCG, which was preceded by a priming injection of $5 \mathrm{IU}$ eCG $48 \mathrm{~h}$ earlier. The cumulus mass and egg were left intact for in vitro fertilization or the cumulus cells were removed with 0.3 $\mathrm{mg} / \mathrm{ml}$ hyaluronidase. In some cases, zonae pellucidae of oocytes and eggs thus collected were removed by a brief treatment in acidic Tyrode's solution (Sigma-Aldrich). Oocytes and eggs from outbred mice [ICR(CD-1), Harlan Laboratories, now Envigo] and inbred mice [C57BL/ 6 J, JAX mice, Jackson Laboratory] were used in these studies as well as transgenic animals, outlined below.

\section{Messenger RNA isolation and CDNA synthesis for analysis of mRNAs for Ywha isoforms}

Oocytes and eggs from ICR(CD-1) mice and C57BL/6 J mice were used for mRNA analysis. Messenger RNA was isolated from $50 \mu \mathrm{L}$ pools of 25 oocyte- and 25 egg- lysates using the Dynabeads mRNA DIRECT ${ }^{\mathrm{mm}}$ kit (Thermo Fisher) following the manufacturer's directions. The mRNA was then eluted off the Oligo $(\mathrm{dT})_{25}$ beads with $10 \mathrm{mM}$ Tris-HCl. First strand complementary DNA stocks were prepared using the QuantiTect Reverse Transcription kit (Qiagen) following the manufacturer's instructions. Two reaction mixtures of $\mathrm{cDNA}$ were made using $5 \mu \mathrm{L}$ mRNA for each mRNA stock.

Primers were designed for each $Y w h a$ isoform transcript and for histone H2AfZ (positive PCR control) using the 
NCBI Primer-BLAST program and were designed according to published mouse mRNA data (see Table 2). All primers were designed to span exon-exon junctions. Amplification of mRNA of the housekeeping gene, H2AfZ, was used as a control. The PCR protocol included 35 cycles of amplification. The PCR products were run on a $2 \%$ agarose gel stained with GelRed Nucleic Acid Stain (Phenix) and visualized during exposure to UV light. To confirm the identity of each YWHA isoform, in a parallel experiment, PCR products were sequenced. PCR products were isolated from the residual PCR buffers and primers by DNA Clean and Concentrator - 5 (D4003, Zymo Research) spin columns. The purified PCR DNA template was sequenced by Eurofins MWG Operon using specific primers.

\section{Single cell sequencing for mRNA of Ywha isoforms}

Single oocytes were isolated in PBS and processed by SingulOmics (New York) for RNA sequencing and data analysis. The computational pipeline for expression quantification was primarily based on STAR aligner and Cufflinks software tool. Reads from RNA-seq were subjected to quality control using FastQC (version 0.11.4), quality trimming using Trim_Galore (version 0.4.1) and aligned to mouse reference genome (GRCM38.91) using STAR (version 020201; options: -outSAMattrIHstart0-outSAMstrandField intronMotif--outFilterIntronMotifs RemoveNoncanonical--alignIntronMin 20--alignIntronMax 1,000,000-outFilterMultimapNmax 1). Duplicated reads were discovered using Picard tools (version 1.119) and removed. Gene annotations (gtf file; version GRCM38.91) were obtained from Ensembl. FPKM values of genes were estimated using cufflinks (version 2.2.1). FPKM values give some qualitative and quantitative estimate of gene expression. Data was obtained for oocytes collected from females of the wild type, ICR(CD1). Oocytes were also obtained from the oocytespecific knockouts of Ywhae and Ywhah, and the oocyte-specific double knockout for Ywhae and Ywhah. Additionally, we examined an oocyte from a female in which the Ppp $1 C C$ gene is globally inactivated in mice with a ICR(CD-1) background; this oocyte provided one additional cell for comparison. Absence of the Pppp1CC does not appear to reduce female fertility. This line has been described previously and is well studied $[72,73]$.

\section{Microinjection of RNA constructs mCherry-YWHAH, EGFP- YWHAE and mCherry-CDC25B}

Messenger RNA constructs were designed and analyzed using SnapGene Viewer. Sequences for EGFP (717 bp) or mCherry $(708 \mathrm{pb})$ fluorescent probes were added to the N-terminal sequences of mouse Ywhah (741 bp), Ywhae (768 bp) or Cdc25b (variant 1, $1731 \mathrm{pb}$ ). A 3xGGGGS (Glycine and Serine residue) linker was added between the fluorescent probe and the target sequence to provide flexibility for fusing of the two proteins. The mRNA was synthesized by TriLink Biotechnologies (San Diego, CA) and the final product included the company's proprietary 3' CleanCap'. The concentration and quality of final the product was determined by quality control and gel analysis. Oocytes were injected using a semi-quantitative pneumatic pressure injection system described previously [55]. Approximately $10 \mathrm{pL}$ of $25 \mu \mathrm{g} /$ $\mathrm{mL}$ mRNA was injected into the cytoplasm of each GVintact mouse oocyte, giving a final concentration of approximately $1.25 \mathrm{ng} / \mu \mathrm{L}$ mRNA, assuming an oocyte volume of $200 \mathrm{pL}$. The injection solution contained mRNA for each of the proteins examined individually or in specific combination at the same final concentration of each for co-localization and FRET analyses. The injected oocytes were incubated in HEPES-buffered MEM with dbcAMP in a humidified chamber at $37^{\circ} \mathrm{C}$ and examined the following day. All injected cells display strong fluorescence of EGFP and mCherry-labeled proteins.

\section{Immunofluorescence}

To examine the initial stages of oocyte maturation and the distribution of $\mathrm{CDC} 25 \mathrm{~B}$, oocytes were isolated in MEM containing $0.1 \mathrm{mg} / \mathrm{mL}$ dbcAMP and examined by confocal immunofluorescence microscopy using a rabbit anti-CDC25B. Cells were fixed immediately in $3.7 \%$ formaldehyde (Time $0 ; 7$ cells), or fixed at $30 \mathrm{~min}$ (12 cells),

Table 2 Primers used to detect the presence of each Ywha isoform by RT-PCR

\begin{tabular}{|c|c|c|c|}
\hline Gene & Forward Primer & Reverse Primer & Product Size \\
\hline Ywhab & 5'-AACGATGTGCTGGAGCTGT-3' & 5'-CGGATGCAACTTCAGAAAGA-3' & $121 \mathrm{bp}$ \\
\hline Ywhae & 5'-CAGAACTGGACACGCTGAGT-3' & 5'-TTCTGCTCTTCACCATCACC-3' & $118 \mathrm{bp}$ \\
\hline Ywhah & 5'-CATGAAGGCGGTGACAGA-3' & 5'-TAACCCTCCAAGAAGATCGC-3' & $110 \mathrm{bp}$ \\
\hline Ywhag & 5'-TCCTTCTITCCAGCCGATCC-3' & 5'-GTTCAGCTCGGTCACGTTCTT-3' & $139 \mathrm{bp}$ \\
\hline Ywhaq & 5'-CGGTGGCCTACAAAAACGTG-3' & 5'-ACAATTCCAGGACCGTGGTG-3' & $168 \mathrm{bp}$ \\
\hline Ywhaz & 5'-CCAGCGACCACCCATTGT-3' & 5'-ACGATGACGTCAAACGCTTC-3' & $139 \mathrm{bp}$ \\
\hline Sfn & 5'-TGTGGCGAAGACTAGGAGGA-3' & 5'-GTCTCGAGAGTAACGCTGGG-3' & $134 \mathrm{bp}$ \\
\hline$H 2 A f Z$ & 5'-TGCAGCTTGCTATACGTGGA-3' & 5'-TCCTTTCTTCCCGATCAGCG-3' & $110 \mathrm{bp}$ \\
\hline
\end{tabular}


$1 \mathrm{~h}$ (8 cells) and $2 \mathrm{~h}$ (6 cells) after transfer to MEM $\alpha$ containing no dbcAMP. After fixation, the oocytes and eggs were washed in PBS-PVA (PBS containing 1\% PVA), permeabilized with $1 \%$ Triton $\mathrm{X}-100$ to promote antibody penetration, washed in PBS-PVA, treated with blocking buffer (5\% normal donkey serum) and incubated overnight with primary antibody. Following washing in blocking buffer ( $1 \%$ donkey serum), the cells were incubated with appropriate secondary antibody for several hours, washed again, and individually imaged. The primary antibody used in the time course assay was rabbit anti-CDC25B (Proteintech; \#10644-1-AP) diluted $1: 200$, and the secondary antibody used was donkey anti-rabbit ( $549 \mathrm{~nm}$-conjugated; Jackson ImmunoResearch Laboratories) diluted 1:200. Dilutions were made in $1 \%$ donkey serum blocking buffer. Three control oocytes were processed through identical procedure stated above but without incubation in the primary antibody.

\section{In situ proximity ligation assays (PLA) to detect interaction of YWHA isoforms with CDC25B in mouse oocytes and eggs}

Duolink in situ PLA probes, blocking solution, antibody diluents, wash buffers $\mathrm{A}$ and $\mathrm{B}$, and detection reagents were obtained from OLink Bioscience (currently distributed by Sigma-Aldrich). Following fixation and permeabilization, the cells were processed following the manufacturer's instructions for the Duolink in situ PLA kit as previously described [55] with primary antibodies for the YWHA isoforms (rabbit anti-14-3-3 isoform panel PAN017, AbD Serotec; diluted 1:200 in Duolink in situ antibody diluent) and with the primary antibody for CDC25B (goat anti-CDC25B, Santa Cruz, sc-6948; diluted 1:200 in Duolink in situ antibody diluent). Confocal Z-stack images of cells were captured at $3 \mu \mathrm{m}$ thickness intervals, with a $60 \mathrm{X}$ oil immersion lens at a zoom setting of 2.5 for multiple oocytes and eggs for each isoform tested. The experiments utilized a panel of antibodies (\#PAN017; AbD Serotec) that was shown to be specific for the various YWHA isoforms in a variety of cell types [42, 74-76]. The goat antiCDC25B antibody used in these experiments appears to be specific as it co-localized with a rabbit antiCDC25B antibody directed at a different epitope on the same protein, and with a phospho-specific antimouse CDC25B antibody. Control oocytes and eggs were processed simultaneously for in situ PLA following identical procedure in absence of the primary antibodies.

To confirm that the PLA method was effective in identifying the close proximity of two different antibodies under the conditions used in these experiments, three oocytes were processed for in situ PLA using two different antibodies to CDC25B. In this case, each of the antibodies was targeted to the same protein. The first was an antibody raised in goat against a peptide mapping at the $\mathrm{N}$-terminus of $\mathrm{CDC} 25 \mathrm{~B}$ of human origin, which reacts also with mouse CDC25B. This antibody was used in studying YWHA and CDC25B intractions, and the second antibody was made in rabbit against a different epitope of CDC25B of human origin, which is known to react with mouse CDC25B. Three control oocytes were processed simultaneously for in situ PLA following identical procedure in absence of the primary antibodies.

\section{Förster resonance energy transfer (FRET) by sensitized emission}

$\mathrm{ICR}(\mathrm{CD}-1)$ oocytes were co-injected with mRNA for two fluorescently labeled proteins and cultured overnight, as indicated above. Cells microinjected with mRNA encoding donor (EGFP) protein or acceptor (mCherry) protein were imaged separately to account for donor and acceptor spectral bleed-through. However, for this FRET pair there is little bleed-through. Olympus FV software was used for the analysis of FRET interactions between mCherry-YWHAH and EGFP-CDC25B, and between EGFP-YWHAE and mCherry-YWHAH. Twelve oocytes were examined for YWHAH and CDC25B interactions and five oocytes for the interaction between YWHAH and YWHAE.

\section{Microinjection of R18}

R18 peptide (Enzo Life Sciences), dissolved in sterile deionized water, was microinjected as described above, into ICR(CD-1) mouse oocytes, to inhibit interactions of all isoforms of YWHA with their potential binding partners including CDC25B. Ten $\mathrm{pL}$ of a $10 \mathrm{mg} / \mathrm{mL}$ stock solution of R18 (approximately 5\% of the oocyte cell volume) was injected into the cytoplasm of the oocyte. Typically, a concentration of $0.1 \mathrm{mg} / \mathrm{mL}$ dibutyryl cAMP (dbcAMP) in the oocyte collection medium is enough to maintain the meiotic arrest in isolated mouse oocytes. We determined the threshold or critical concentration of dbcAMP, just sufficient to maintain prophase I arrest in at least $75 \%$ of oocytes cultured overnight, to be 0.05 $\mathrm{mg} / \mathrm{mL}$. Following injection, the cells were transferred through several washes and incubated in bicarbonate buffered MEM $\alpha$ containing the threshold concentration of dbcAMP in the presence of $5 \% \mathrm{CO}_{2}$ at $37^{\circ} \mathrm{C}$ for $13 \mathrm{~h}$ and then examined. Controls included oocytes processed simultaneously through identical procedure, following injection of $10 \mathrm{pL}$ sterile deionized water or with no injection. 


\section{Microinjection of translation-blocking morpholinos against messages for Ywha isoforms}

GV-intact ICR(CD-1) oocytes were isolated and microinjected, as described above, with $10 \mathrm{pL}$ of $2 \mathrm{mM}$ stock morpholino oligonucleotide (Gene Tools; final concentration $0.1 \mathrm{mM}$ in each cell) against each of the seven Ywha isoform messages. The cells were then incubated for $24 \mathrm{~h}$ in bicarbonate-buffered MEM $\alpha$ containing dbcAMP $(0.1 \mathrm{mg} / \mathrm{mL})$ to prevent maturation and to allow degradation of the existing proteins. The cells were then transferred through several washes and incubated in bicarbonate-buffered MEM $\alpha$ containing $0.05 \mathrm{mg} / \mathrm{mL}$ dbcAMP in the presence of $5 \% \mathrm{CO}_{2}$ at $37^{\circ} \mathrm{C}$ for $13 \mathrm{~h}$ and examined for intact GV or evidence of GVBD. The number of cells with completed GVBD after injection of morpholino oligonucleotide against each of the $Y w h a$ isoform messages was compared to the number of cells with GVBD in control uninjected cells and those injected with a standard, nonsense morpholino.

For experiments involving microinjections of R18 and morpholinos against $Y w h a$ isoform messages, at each injection condition the cells were classified as having intact GV or having undergone GVBD; therefore, a non- parametric statistical analysis was done using Fisher's exact test $(2 \times 2$ contingency table). First, uninjected cells and control injected cells (deionized water for R18 experiments and a standard, nonsense morpholino for the morpholino experiments) were compared. Then, each experimental condition was compared to the control injection condition (water or the nonsense morpholino). Two-tailed $P$ values are presented and a value of less than 0.05 is considered to indicate a significant difference.

\section{Conditional and global knockouts for Ywhah and Ywhae isoforms}

We produced a mouse line in which exon 2 of the mouse $Y$ whah gene was flanked by LoxP sites. The conditional knockout mouse line was produced by a commercial company (Cyagen Biosciences, Santa Clara, CA) using standard ES cell-based gene targeting. Exon 2 of the mouse Ywhah gene was selected as the conditional knockout region (see Fig. 9). The targeting vector, 5' homology arm, 3' homology arm and CKO regions were amplified from BAC DNA and confirmed by end sequencing. The targeting vector was electroporated into C57BL/6 ES cells. Clones were screened by

\section{4-3-3 wildtype allele}

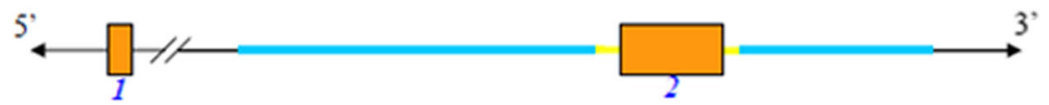

Targeting vector

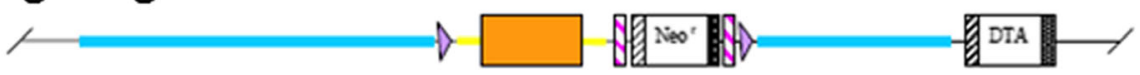

Targeted allele

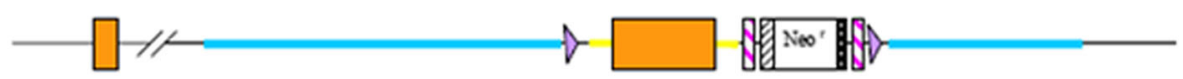

Conditional KO allele (after Flp recombination
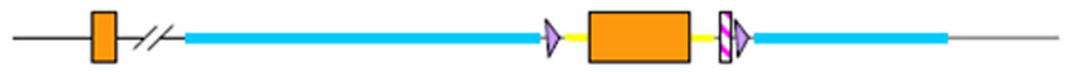

Conditional KO allele (after CRE recombination

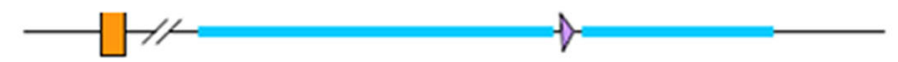

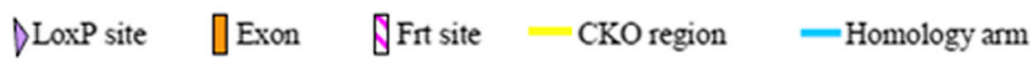

Fig. 9 Diagrammatic summary of the production of Ywhah oocyte-specific conditional knockout. Exons 1 and 2 of the Ywhah gene are represented by orange boxes. The targeting vector and homology arms are indicated. The vector was electroporated into C57BL/6 ES cells, chimeras were produced, and germ line transmission in C57BL/6 J was confirmed. Exon 2 is removed following Cre recombination (see Methods) 
PCR and selected by Southern blot. ES cells were injected into B6-albino mice blastocyts and the chimera produced were bred for germline transmission. Progeny containing the floxed gene were mated with $\mathrm{C} 57 \mathrm{BL} / 6 \mathrm{~J}$ mice to obtain a colony on this strain. Mice homozygous for the LoxP in the Ywhah gene were mated with ZP3-Cre (C57BL/6$\mathrm{Tg}(\mathrm{Zp} 3$-cre), The Jackson Laboratory) or ACTB-Cre mice (B6N.FVB-Tmem163 ${ }^{\text {Tg(ACTB-cre)2Mrt } / C j D s w J, ~ T h e ~}$ Jackson Laboratory). Progeny of these mating pairs were examined by PCR to show disruption of the gene and/or by protein analysis to show loss of protein. These mice were used for in vivo breeding, oocyte analyses, oocyte maturation and in some cases, for in vitro fertilization studies.

We also obtained a mouse line with LoxP sites inserted in the Ywhae gene from Dr. K. Toyo-oka (Drexel University). These mice contain LoxP sites to remove exons 3 and 4 of the Ywhae gene with Cre recombinase and have been successfully used to study the role of YWHAE protein in the developing brain $[51,77]$. Mice were maintained in the floxed condition in $129 / \mathrm{SvEv}$ mice and animals homozygous for the LoxP in the Ywhae gene were mated with ZP3-Cre or ACTB-Cre mice. We also cross bred both LoxP Ywhah and Ywhae lines to get a homozygous mouse line for both genes and mated those mice with the ZP3-Cre line to knockout both genes.

Unique primers were used in PCR to confirm disruption of the Ywhah and Ywhae genes (see Table 3) using DNA from ear-punches or, in some cases, from oocytes. The Ywhah LoxP primer distinguished the mice that carried the flanked gene from the wild type. The size for the flanked gene is $292 \mathrm{bp}$, while the wild-type gene is 226 bp. Heterozygous LoxP animals expressed two different bands with two different sizes: one for the wild type and another for the flanked gene. Absence of any band indicated disruption of the gene. In addition, primers external to the gene knockout region were used to confirm the knockout condition, producing a band at $390 \mathrm{bp}$. The Ywhae LoxP primer distinguished the mice that carry the flanked gene from the wild type condition. The band-size for the flanked gene is $536 \mathrm{bp}$, while the wild-type gene is $450 \mathrm{bp}$. The heterozygous condition would express two different bands at two different sizes: one for the wild-type and the other for the flanked gene. Absence of any band indicated disruption of the gene. In addition, primers external to the gene knockout region were used to confirm the knockout condition, producing a band at $664 \mathrm{bp}$. A generic Cre primer set detected the sequence of the Cre that was found in both $\mathrm{ZP} 3$ and ACTB lines. The band at $100 \mathrm{bp}$ confirms the presence of the Cre.

Homozygous WT, homozygous LoxP with no Cre and LoxP/WT with no Cre, are effectively wild-type females, which served as control animals in some cases (generally litter mates) along with true wild-type animals. LoxP/ WT with Cre positive, -/WT, -/LoxP with Cre negative and WT/LoxP with ZP3 Cre positive were taken as heterozygous females. The ZP3 conditional knockout expressed -/LoxP with ZP3 Cre positive in ear-punch while the oocytes do not express the gene. The global knockout females were homozygous for the knockout $(-/-)$ in all cells, as identified by the primers listed in Table 3.

\section{Western blotting for knockout mice}

In several cases, we confirmed the knockout condition in ovary or oocyte cell lysates using specific antibodies in Western blots. Cell lysates were prepared from oocytes, eggs and 2-cell embryos in a homogenizing buffer (Tris-HCl $10 \mathrm{mM}$ pH 7.0, EGTA $1 \mathrm{mM}$ and EDTA $1 \mathrm{mM} \mathrm{pH} \mathrm{8.0,} \mathrm{Protease} \mathrm{and} \mathrm{Phosphatase}$ Inhibitor Cocktail (Sigma-Aldrich \# PPC1010). Laemmli sample buffer $(5 \mathrm{X}$, containing Tris- $\mathrm{HCl} \mathrm{pH}$ 6.8-7.0, glycerol 50\%, SDS 5\%, bromophenol blue $0.05 \%$ and DTT $250 \mathrm{mM}$ ) was then added and the lysate was boiled for $5 \mathrm{~min}$ at $95^{\circ} \mathrm{C}$. Cell lysates were separated in a $12 \%$ polyacrylamide gel and the proteins were transferred by electrophoresis to a PVDF membrane (Amersham Hybond P 0.2 PVDF 10600021) and blocked with $5 \%$ non-fat dry milk in TTBS (0.2 M Tris, pH 7.4, $1.5 \mathrm{M} \mathrm{NaCl}, 0.1 \%$ thimerosal and $0.5 \%$ Tween 20). The blots were incubated

Table 3 Primers used to detect LoxP and Ywhah

\begin{tabular}{|c|c|c|}
\hline PCR product & PCR primers & Fragment size (bp) \\
\hline Ywhah LoxP & $\begin{array}{l}\text { Forward: 5'- TAATTGTGAGCCACCCGAAATGA - 3' } \\
\text { Reverse: 5'- GCCAACGACCAATGCCAATTATAG - 3' }\end{array}$ & $\begin{array}{l}\text { WT: } 226 \\
\text { Floxed: } 292\end{array}$ \\
\hline Ywhah knockout & $\begin{array}{l}\text { Forward: 5'- CCTGATCTAGGATAGCTAGGGCTACATAG - 3' } \\
\text { Reverse: 5'- AGTATACCTTITGGAGACAGGATCTATTATAGCC - 3' }\end{array}$ & Deletion gives band at: 390 \\
\hline Ywhae LoxP & $\begin{array}{l}\text { Forward: 5'- GCATGTGTITGTCTGTCAGAGGAC - 3' } \\
\text { Reverse: 5'- AGGTACCAAAACAGTAAGCCATCTCCCTA - 3' }\end{array}$ & $\begin{array}{l}\text { WT: } 450 \\
\text { Floxed: } 536\end{array}$ \\
\hline Ywhae knockout & $\begin{array}{l}\text { Forward: 5'- TTCTाITGTAGAAATTGGGGAAGGTCATGG - 3' } \\
\text { Reverse: 5'- AGGTACCAAAACAGTAAGCCATCTCCCTA - 3' }\end{array}$ & Deletion gives band at: 664 \\
\hline Generic Cre & $\begin{array}{l}\text { Forward: 5'- GCG GTC TGG CAG TAA AAA CTA TC - 3' } \\
\text { Reverse: 5'- GTG AAA CAG CAT TGC TGT CAC TT - 3' }\end{array}$ & Cre Positive: 100 \\
\hline
\end{tabular}


with primary antibody overnight at $4{ }^{\circ} \mathrm{C}$ [YWHAH: mouse monoclonal anti-YWHAH (Novus Biological, NBP1-92691, 1:5000 dilution) or goat anti-YWHAH (R\&D Systems AF4420, 1:1000 dilution); YWHAE: anti-YWHAE (Santa Cruz, sc-23,957, 1:1000 dilution)]. The blots were then washed with TTBS twice for $15 \mathrm{~min}$ each and incubated with the appropriate secondary antibody conjugated to horseradish peroxidase for at least $1 \mathrm{~h}$ at room temperature. The blots were then washed with TTBS twice for $15 \mathrm{~min}$ each and twice for $5 \mathrm{~min}$ each. Finally, the blots were developed with Amersham ECL Prime Western Blotting Detection Reagent (Amersham, RPN2232) and imaged.

\section{In vitro fertilization}

Male reproductive tissue was removed from male mice following euthanasia (as described above for the collection of oocytes and eggs). Sperm were collected by puncture and snipping of each cauda epididymis and vas deferens of three- to five-month old wild-type male mice in a $1000 \mu \mathrm{L}$ drop of HTF media (Millipore: EmbryoMax ${ }^{\circ}$ Human Tubal Fluid) and cultured at $37^{\circ} \mathrm{C}$ under $5 \% \mathrm{CO}_{2}$ in a humidified incubator for $10 \mathrm{~min}$ to allow the sperm to swim out. The tissues were removed from the drop after $10 \mathrm{~min}$ and sperm were maintained in the incubator for $45 \mathrm{~min}$ to allow for capacitation. Eggs were obtained from two- to three-month old wild type and Ywhae oocyte-specific knockout females following superovulation induced by intraperitoneal injection of $5 \mathrm{IU}$ of eCG (Sigma-Aldrich) and 46-50 h later, injection of 5 IU of hCG (Sigma-Aldrich). Oocyte/cumulus complexes were removed from the ampullae 13-15 h after hCG injection and transferred to a $135 \mu \mathrm{l}$ drop of HTF covered with mineral oil. After capacitation, $15 \mu \mathrm{L}$ of the sperm suspension was added to the $135 \mu \mathrm{L}$ drop of containing oocyte/cumulus complexes. The dish was incubated at $37^{\circ} \mathrm{C}$ in $5 \% \mathrm{CO}_{2}$ for $4 \mathrm{~h}$. The eggs were then washed by pipetting into fresh media (removing dissociated cumulus cells) and incubated overnight in a $300 \mu \mathrm{L}$ drop of HTF medium at $37{ }^{\circ} \mathrm{C}$ and $5 \% \mathrm{CO}_{2}$. The following day, the number of two-cell embryos was counted. Some two-cell embryos were cultured to blastocyst stage.

\footnotetext{
Abbreviations

CDC25B: Cell division cycle 25B; dbcAMP: Dibutyryl cyclic adenosine monophosphate; eCG: Equine Chorionic Gonadotropin; FITC: Fluorescein Isothiocyanate; GV: Germinal Vesicle; GVBD: Germinal Vesicle Breakdown; hCG: Human Chorionic Gonadotropin; HTF: Human Tubal Fluid (media); IBMX: 3-Isobutyl-1-methylxanthine; MEM: Minimal Essential Medium; PKA: Protein Kinase A; PLA: Proximity Ligation Assay; PMSF: Phenylmethylsulfonyl fluoride; R18: YWHA inhibitor peptide; SFN: Stratifin (14-3-30); Tris-HCl: Tris-Hydrochloride; TTBS: Tris Buffered Saline with Tween 20; YWHA: Tyrosine 3-Monooxygenase/Tryptophan 5Monooxygenase Activation protein (14-3-3) YWHAB: Tyrosine 3Monooxygenase/Tryptophan 5-Monooxygenase Activation protein, Beta polypeptide (14-3-33); YWHAE: Tyrosine 3-Monooxygenase/Tryptophan 5-
}

Monooxygenase Activation protein, Epsilon polypeptide (14-3-3z); YWHAG: Tyrosine 3-Monooxygenase/Tryptophan 5-Monooxygenase Activation protein, Gamma polypeptide (14-3-3ץ); YWHAH: Tyrosine 3Monooxygenase/Tryptophan 5-Monooxygenase Activation protein, Eta polypeptide (14-3-3n); YWHAQ: Tyrosine 3-Monooxygenase/Tryptophan 5Monooxygenase Activation protein, Theta/Tau polypeptide (14-3-3t); YWHAZ: Tyrosine 3-Monooxygenase/Tryptophan 5-Monooxygenase Activation protein, Zeta polypeptide (14-3-3Z)

\section{Acknowledgements}

The authors are grateful to Dr. Kazuhito Toyo-oka for providing the Ywhae conditional knockout mouse line and Dr. Michael Model for substantial assistance with cellular imaging. They also thank the following former students who particiapted in the project: Adam Schulte, Michele Fabian, Angela Reese, Sourabh Dhawan, Travis Mollick, Shawn Davis, Cyrus Mozena and Daniel Letwin.

\section{Authors' contributions}

AE oversaw the breeding of transgenic mice, acquired and analyzed the data, and drafted portions of the manuscript. SD oversaw and performed the CDC25B time course assay, protein interaction and R18 and morpholino microinjection experiments, acquired and analyzed the data, and drafted portions of the manuscript. AD performed the Ywha isoform mRNA analysis. EG generated tagged proteins, performed the experiments and analyzed the data. Al performed a variety of essential data collection and analyses. SV and DK contributed to the conception of the work, participated in the experiments, assisted in interpreting the data and revising the manuscript. All authors read and approved the final manuscript.

\section{Funding}

This work was supported by the Eunice Kennedy Shriver National Institute of Child Health and Human Development of the National Institutes of Health under Award Number HD061869. The funding agency had no input to the design of the study or in the collection, analysis or interpretation of data.

\section{Availability of data and materials}

All data sets used and/or analyzed during the current study are available from the corresponding author on reasonable request.

\section{Ethics approval and consent to participate}

All mice used in the present experiments were housed and used at Kent State University with the approval of the Kent State University Institutional Animal Care and Use Committee following the appropriate laws, guidelines and policies and performed in accordance with the NIH policies.

\section{Consent for publication \\ Not applicable.}

\section{Competing interests}

The authors declare that they have no competing interests.

\section{Author details \\ ${ }^{1}$ School of Biomedical Sciences, Kent State University, Kent, OH 22422, USA. ${ }^{2}$ Department of Biological Sciences, Nova Southeastern University, Fort Lauderdale, FL 33314, USA. ${ }^{3}$ Department of Environmental and Occupational Health, University of Pittsburgh Graduate School of Public Health, UPMC Hillman Cancer Center, Pittsburgh, PA 15213, USA. ${ }^{4}$ Department of Physiology and Biophysics, Case Western Reserve University School of Medicine, Cleveland, OH 44106, USA. ${ }^{5}$ Department of Biological Sciences, Kent State University, Kent, OH 44242, USA.}

Received: 28 February 2019 Accepted: 13 September 2019

Published online: 22 October 2019

\section{References}

1. Mehlmann $L M$, Jones $T L Z$, Jaffe $L A$. Meiotic arrest in the mouse follicle maintained by a G(s) protein in the oocyte. Science. 2002;297(5585):1343-5.

2. Mehlmann LM, Saeki Y, Tanaka S, Brennan TJ, Evsikov AV, Pendola FL, Knowles BB, Eppig JJ, Jaffe LA. The G(s)-linked receptor GPR3 maintains meiotic arrest in mammalian oocytes. Science. 2004;306(5703):1947-50. 
3. DiLuigi A, Weitzman VN, Pace MC, Siano LJ, Maier D, Mehlmann LM. Meiotic arrest in human oocytes is maintained by a Gs signaling pathway. Biol Reprod. 2008;78(4):667-72.

4. Jaffe LA, Egbert JR. Regulation of mammalian oocyte meiosis by intercellular communication within the ovarian follicle. Annu Rev Physiol. 2017;79:237-60.

5. Mitra J, Schultz RM. Regulation of the acquisition of meiotic competence in the mouse: changes in the subcellular localization of cdc2, cyclin B1, cdc25C and wee1, and in the concentration of these proteins and their transcripts. J Cell Sci. 1996;109:2407-15.

6. Kanatsu-Shinohara M, Schultz RM, Kopf GS. Acquisition of Meiotic Competence in mouse oocytes: absolute amounts of p34cdc2, Cyclin B1, cdc25C, and wee1 in Meiotically incompetent and competent Oocytes1. Biol Reprod. 2005;63(6):1610-6

7. Han SJ, Chen R, Paronetto MP, Conti M. Wee1B is an oocyte-specific kinase involved in the control of meiotic arrest in the mouse. Curr Biol. 2005;15:1670-6

8. Oh JS, Han SJ, Conti M. Wee1B, Myt1, and Cdc25 function in distinct compartments of the mouse oocyte to control meiotic resumption. J Cell Biol. 2010;188(2):199-207.

9. Brunet S, Maro B. Cytoskeleton and cell cycle control during meiotic maturation of the mouse oocyte: integrating time and space. Reproduction. 2005;130(6):801-11.

10. Adhikari $D$, Liu K. The regulation of maturation promoting factor during prophase I arrest and meiotic entry in mammalian oocytes. Mol Cell Endocrinol. 2014;382(1):480-7.

11. Masui Y. From oocyte maturation to the in vitro cell cycle: the history of discoveries of maturation-promoting factor (MPF) and cytostatic factor (CSF). Differentiation. 2001;69(1):1-17.

12. Ma HT, Poon RYC. How protein kinases co-ordinate mitosis in animal cells. Biochem J. 2011;435(1):17-31

13. Kishimoto T. MPF-based meiotic cell cycle control: half a century of lessons from starfish oocytes. Proc Japan Acad Ser B. 2018;94:180-203.

14. Zhang Y, Zhang Z, Xu XY, Li XS, Yu M, Yu AM, Zong ZH, Yu BZ. Protein kinase a modulates $C d c 25 B$ activity during meiotic resumption of mouse oocytes. Dev Dyn. 2008;237(12):3777-86.

15. Cui $C$, Zhao H, Zhang Z, Zong Z, Feng C, Zhang Y, Deng X, Xu X, Yu B. CDC25B acts as a potential target of PRKACA in fertilized mouse eggs. Biol Reprod. 2008;79:991-8.

16. Pirino G, Wescott MP, Donovan PJ, Wesco MP, Donovan PJ. Protein kinase a regulates resumption of meiosis by phosphorylation of $\mathrm{Cdc} 25 \mathrm{~B}$ in mammalian oocytes. Cell Cycle. 2009;8(4):665-70.

17. Lincoln AJ, Wickramasinghe D, Stein P, Schultz RM, Palko ME, De Miguel MP, Tessarollo L, Donovan PJ. Cdc25b phosphatase is required for resumption of meiosis during oocyte maturation. Nat Genet. 2002;30(4):446-9.

18. Chen MS, Hurov J, White LS, Woodford-Thomas T, Piwnica-Worms H. Absence of apparent phenotype in mice lacking Cdc25C protein phosphatase. Mol Cell Biol. 2001;21(12):3853-61.

19. Solc P, Saskova A, Baran V, Kubelka M, Schultz RM, Motlik J. CDC25A phosphatase controls meiosis I progression in mouse oocytes. Dev Biol. 2008;317(1):260-9

20. Norris RP, Ratzan WJ, Freudzon M, Mehlmann LM, Krall J, Movsesian MA, Wang $\mathrm{H}$, Ke H, Nikolaev VO, Jaffe LA. Cyclic GMP from the surrounding somatic cells regulates cyclic AMP and meiosis in the mouse oocyte. Development. 2009;136(11):1869-78.

21. Jones KT. Turning it on and off: M-phase promoting factor during meiotic maturation and fertilization. Mol Hum Reprod. 2004;10(1):1-5.

22. Mehlmann LM. Stops and starts in mammalian oocytes: recent advances in understanding the regulation of meiotic arrest and oocyte maturation. Reproduction. 2005;130(6):791-9.

23. Duckworth BC, Weaver JS, Ruderman JV. G2 arrest in Xenopus oocytes depends on phosphorylation of cdc25 by protein kinase a. Proc Natl Acad Sci. 2002;99(26):16794-9.

24. Conklin DS, Galaktionov K, Beach D. 14-3-3-proteins associate with Cdc25phosphatases. Proc Natl Acad Sci U S A. 1995:92(17):7892-6.

25. Uchida S, Kuma A, Ohtsubo M, Shimura M, Hirata M, Nakagama H, Matsunaga T, Ishizaka Y, Yamashita K. Binding of 14-3-3beta but not 14-33sigma controls the cytoplasmic localization of CDC25B: binding site preferences of 14-3-3 subtypes and the subcellular localization of CDC25B. J Cell Sci. 2004;117(14):3011-20.

26. Freeman AK, Morrison DK. 14-3-3 proteins: diverse functions in cell proliferation and cancer progression. Semin Cell Dev Biol. 2011;22(7):681-7.
27. Meek SEM, Lane WS, Piwnica-Worms H. Comprehensive proteomic analysis of interphase and mitotic 14-3-3-binding proteins. J Biol Chem. 2004; 279(31):32046-54

28. Giles N, Forrest A, Gabrielli B. 14-3-3 acts as an intramolecular bridge to regulate cdc25b localization and activity. J Biol Chem. 2003;278(31):28580-7.

29. Kumagai A, Yakowec PS, Dunphy WG. 4-3-3 proteins act as negative regulators of the mitotic inducer Cdc25 in Xenopus egg extracts. Mol Biol Cell. 1998;9:345-54.

30. Margolis SS, Kornbluth S. When the checkpoints have gone - insights into Cdc25 functional activation. Cell Cycle. 2004;3(4):425-8.

31. Perdiguero $E$, Nebreda AR. Regulation of Cdc 25 C activity during the meiotic G(2)/M transition. Cell Cycle. 2004;3(6):733-7.

32. Gardino AK, Yaffe MB. 14-3-3 proteins as signaling integration points for cell cycle control and apoptosis. Semin Cell Dev Biol. 2011;22(7):688-95.

33. Aitken A. 14-3-3 proteins: a historic overview. Semin Cancer Biol. 2006;16(3):162-72.

34. Morrison DK. The 14-3-3 proteins: integrators of diverse signaling cues that impact cell fate and cancer development. Trends Cell Biol. 2009; 19(1):16-23.

35. Mackintosh C. Dynamic interactions between 14-3-3 proteins and phosphoproteins regulate diverse cellular processes. Biochem J. 2004;381:329-42.

36. Puri $P$, Stahler R, Chen $Y$, Acker-Palmer A, Kline D, Vijayaraghavan S. Identification of testis 14-3-3 binding proteins by tandem affinity purification. Spermatogenesis. 2011;1(4):354-65.

37. Puri P, Myers K, Kline D, Vijayaraghavan S. Proteomic analysis of bovine sperm YWHA binding partners identify proteins involved in signaling and metabolism. Biol Reprod. 2008;79(6):1183-91.

38. Snow AJ, Puri P, Acker-Palmer A, Bouwmeester T, Vijayaraghavan S, Kline D. Phosphorylation-dependent interaction of tyrosine 3-monooxygenase/ tryptophan 5-monooxygenase activation protein (YWHA) with PADI6 following oocyte maturation in mice. Biol Reprod. 2008;79(2):337-47.

39. Rose R, Rose M, Ottmann C. Identification and structural characterization of two 14-3-3 binding sites in the human peptidylarginine deiminase type VI. J Struct Biol. 2012;180:65-72.

40. Dougherty MK. Unlocking the code of 14-3-3. J Cell Sci. 2004;17(10):1875-84.

41. Aitken A, Baxter H, Dubois T, Clokie S, Mackie S, Mitchell K, Peden A, Zemlickova E. Specificity of 14-3-3 isoform dimer interactions and phosphorylation. Biochem Soc Trans. 2002;30:351-60.

42. De S, Marcinkiewicz JL, Vijayaraghavan S, Kline D. Expression of 14-3-3 protein isoforms in mouse oocytes, eggs and ovarian follicular development. BMC Res Notes. 2012;5:57. http://www.biomedcentral.com/1 756-0500/5/57. Accessed 23 Jan 2012

43. Meng J, Cui C, Liu Y, Jin M, Wu D, Liu C, Wang E, Yu B. The role of 14-3-3 epsilon interaction with phosphorylated Cdc25B at its Ser321 in the release of the mouse oocyte from prophase I arrest. PLoS One. 2013;8(1):e53633.

44. Pan H, Ma P, Zhu W, Schultz RM. Age-associated increase in aneuploidy and changes in gene expression in mouse eggs. Dev Biol. 2008;316(2):397-407.

45. Grøndahl ML, Yding Andersen C, Bogstad J, Nielsen FC, Meinertz H, Borup R. Gene expression profiles of single human mature oocytes in relation to age. Hum Reprod. 2010;25(4):957-68.

46. Grøndahl ML, Borup R, Vikesa J, Ernst E, Andersen CY, Lykke-Hartmann K. The dormant and the fully competent oocyte: comparing the transcriptome of human oocytes from primordial follicles and in metaphase II. Mol Hum Reprod. 2013:19(9):600-17.

47. Steinacker $P$, Schwarz $P$, Reim $K$, Brechlin $P$, Jahn $O$, Kratzin $H$, Aitken A, Wiltfang J, Aguzzi A, Bahn E, Baxter HC, Brose N, Otto M. Unchanged survival rates of 14-3-3 gamma knockout mice after inoculation with pathological prion protein. Mol Cell Biol. 2005;25(4):1339-46.

48. Gittenberger-de Groot AC, Hoppenbrouwers T, Miquerol L, Kosaka Y, Poelmann RE, Wisse LJ, Yost HJ, Jongbloed MRM, Deruiter MC, Brunelli L. 14-3-3epsilon controls multiple developmental processes in the mouse heart. Dev Dyn. 2016;245(11):1107-23.

49. Toyo-oka K, Shionoya A, Gambello MJ, Cardoso C, Leventer R, Ward HL, Ayala R, Tsai LH, Dobyns W, Ledbetter D, Hirotsune S, Wynshaw-Boris A. $14-3-3 \varepsilon$ is important for neuronal migration by binding to NUDEL: a molecular explanation for miller-Dieker syndrome. Nat Genet. 2003;34(3): 274-85.

50. Cheah PS, Ramshaw HS, Thomas PQ, Toyo-Oka K, Xu X, Martin S, Coyle P, Guthridge MA, Stomski F, van den Buuse M, Wynshaw-Boris A, Lopez AF, Schwarz QP. Neurodevelopmental and neuropsychiatric behaviour defects arise from 14-3-3Z deficiency. Mol Psychiatry. 2012;17(4):451-66. 
51. Toyo-oka K, Wachi T, Hunt RF, Baraban SC, Taya S, Ramshaw H, Kaibuchi K, Schwarz QP, Lopez AF, Wynshaw-Boris A. 14-3-3 $\varepsilon$ and $\zeta$ regulate neurogenesis and differentiation of neuronal progenitor cells in the developing brain. J Neurosci. 2014;34(36):12168-81.

52. Fredriksson S, Gullberg M, Jarvius J, Olsson C, Pietras K, Gústafsdóttir SM, Ostman A, Landegren U. Protein detection using proximity-dependent DNA ligation assays. Nat Biotechnol. 2002;20(5):473-7.

53. Weibrecht I, Leuchowius K-J, Clausson C-M, Conze T, Jarvius M, Howell WM, Kamali-Moghaddam M, Söderberg O. Proximity ligation assays: a recent addition to the proteomics toolbox. Expert Rev Proteomics. 2010; 7(3):401-9.

54. Söderberg O, Gullberg M, Jarvius M, Ridderstråle K, Leuchowius KJ, Jarvius J, Wester K, Hydbring P, Bahram F, Larsson LG, Landegren U. Direct observation of individual endogenous protein complexes in situ by proximity ligation. Nat Methods. 2006;3(12):995-1000.

55. De S, Kline D. Evidence for the requirement of 14-3-3eta (YWHAH) in meiotic spindle assembly during mouse oocyte maturation. BMC Dev Biol. 2013;13:10. http://www.biomedcentral.com/1471-213X/13/10.

56. Lan ZJ, Xu X, Cooney AJ. Differential oocyte-specific expression of Cre recombinase activity in GDF-9-iCre, Zp3cre, and Msx2Cre transgenic mice. Biol Reprod. 2004;71(5):1469-74.

57. Lewandoski M, Meyers EN, Martin GR. Analysis of Fgf8 gene function in vertebrate development. Cold Spring Harb Symp Quant Biol. 1997; 62:159-68.

58. Potireddy S, Vassena R, Patel BG, Latham KE. Analysis of polysomal mRNA populations of mouse oocytes and zygotes: dynamic changes in maternal mRNA utilization and function. Dev Biol. 2006:298:155-66.

59. Cui C, Ren X, Liu D, Deng X, Qin X, Zhao X, Wang E, Yu B. 14-3-3 epsilon prevents $\mathrm{G} 2 / \mathrm{M}$ transition of fertilized mouse eggs by binding with $C D C 25 B$. BMC Dev Biol. 2014;14:33.

60. Uchida S, Kubo A, Kizu R, Nakagama H, Matsunaga T, Ishizaka Y, Yamashita K. Amino acids C-terminal to the 14-3-3 binding motif in CDC25B affect the efficiency of 14-3-3 binding. J Biochem. 2006;139(4):761-9.

61. Wang BC, Yang HZ, Liu YC, Jelinek T, Zhang LX, Ruoslahti E, Fu H. Isolation of high-affinity peptide antagonists of 14-3-3 proteins by phage display. Biochemistry. 1999;38(38):12499-504.

62. Masters SC, Fu H. 14-3-3 Proteins Mediate an Essential Anti-apoptotic Signal. J Biol Chem. 2001;276(48):45193-200.

63. Masters SC, Subramanian RR, Truong A, Yang H, Fujii K, Zhang H, Fu H. Survival-promoting functions of 14-3-3 proteins. Biochem Soc Trans. 2002;30:360-5.

64. Peluso JJ, Pappalardo A. Progesterone regulates granulosa cell viability through a protein kinase G-dependent mechanism that may involve 14-3-3 sigma. Biol Reprod. 2004;71(6):1870-8.

65. Wu CL, Muslin AJ. Role of 14-3-3 proteins in early Xenopus development. Mech Dev. 2002;119(1):45-54.

66. Buret $L$, Delprat $B$, Delettre C. Loss of function of Ywhah in mice induces deafness and cochlear outer hair cell's degeneration. Cell Death Dis. 2016;7:e2187.

67. Hermeking $H$, Benzinger A. 14-3-3 proteins in cell cycle regulation. Semin Cancer Biol. 2006;16(3):183-92.

68. Lee J, Kumagai A, Dunphy WG. Positive regulation of Wee1 by Chk1 and 143-3 proteins. Mol Biol Cell. 2001;12(3):551-63.

69. Rothblum-Oviatt CJ, Ryan CE, Piwnica-Worms H. 14-3-3 binding regulates catalytic activity of human Wee1 kinase. Cell Growth Differ. 2001;12(12):581-9.

70. Honda R, Ohba Y, Yasuda H. 14-3-3 zeta protein binds to the carboxyl half of mouse Wee1 kinase. Biochem Biophys Res Commun. 1997;230(2):262-5.

71. Wang Y, Jacobs C, Hook KE, Duan H, Booher RN, Sun Y. Binding of 143-3 beta to the carboxyl terminus of Wee1 increases Wee1 stability, kinase activity, and G(2)-M cell population. Cell Growth Differ. 2000; 11(4):211-9.

72. Sinha N, Puri P, Nairn AC, Vijayaraghavan S. Selective ablation of Ppp1cc gene in testicular germ cells causes Oligo-Teratozoospermia and infertility in Mice1. Biol Reprod. 2013;89:1-15.

73. Chakrabarti R, Kline D, Lu J, Orth J, Pilder S, Vijayaraghavan S. Analysis of Ppp1cc-null mice suggests a role for PP1gamma2 in sperm Morphogenesis1. Biol Reprod. 2007;76:992-1001.

74. Martin H, Patel Y, Jones D, Howell S, Robinson K, Aitken A. Antibodies against the major brain isoforms of 14-3-3-protein - an antibody specific for the $\mathrm{N}$-acetylated amino-terminus of a protein. FEBS Lett. 1993;331(3):296-303.

75. Martin H, Rostas J, Patel Y, Aitken A. Subcellular-localization of 14-3-3isoforms in rat-brain using specific antibodies. J Neurochem. 1994; 63(6):2259-65.

76. Roth D, Morgan A, Martin H, Jones D, Martems GJM, Aitken A, et al. Characterization of 14-3-3-proteins in adrenal Chromaffin cells and demonstration of isoform-specific phospholipid-binding. Biochem J. 1994; 301:305-10.

77. Toyo-oka K, Shionoya A, Gambello MJ, Cardoso C, Leventer R, Ward HL, et al. 14-3-3 epsilon is important for neuronal migration by binding to NUDEL: a molecular explanation for miller-Dieker syndrome. Nat Genet. 2003;34:274-85.

\section{Publisher's Note}

Springer Nature remains neutral with regard to jurisdictional claims in published maps and institutional affiliations.
Ready to submit your research? Choose BMC and benefit from:

- fast, convenient online submission

- thorough peer review by experienced researchers in your field

- rapid publication on acceptance

- support for research data, including large and complex data types

- gold Open Access which fosters wider collaboration and increased citations

- maximum visibility for your research: over $100 \mathrm{M}$ website views per year

At BMC, research is always in progress.

Learn more biomedcentral.com/submissions 